Review

\title{
The Heck Reaction in Ionic Liquids: Progress and Challenges
}

\section{Fabio Bellina * and Cinzia Chiappe *}

Dipartimento di Chimica e Chimica Industriale, via Risorgimento 35, 56126 Pisa, Italy

* Authors to whom correspondence should be addressed; E-Mails: bellina@dcci.unipi.it (F.B.); cinziac@farm.unipi.it (C.C.)

Received: 3 March 2010; in revised form: 22 March 2010 / Accepted: 26 March 2010 /

Published: 30 March 2010

\begin{abstract}
As the interest for environmental increases and environmental laws become more stringent, the need to replace existing processes with new more sustainable technologies becomes a primary objective. The use of ionic liquids to replace organic solvents in metal catalyzed reactions has recently gained much attention and great progress has been accomplished in this area in the last years. This paper reviews the recent developments in the application of ionic liquids and related systems (supported ionic liquids, ionic polymers, and so on) in the Heck reaction. Merits and achievements of ionic liquids were analyzed and discussed considering the possibility of increasing the effectiveness of industrial processes.
\end{abstract}

Keywords: ionic liquids; heck reaction; Pd catalyst; selectivity

\section{Introduction}

Over the past decade, ionic liquids (ILs), salts having melting points lower than $100{ }^{\circ} \mathrm{C}$, have become one of the fastest growing research areas. The application of these remarkable salts as solvents in organic reactions and catalytic processes has been extensively investigated and reviewed [1-9]. The term "ionic liquid" identifies a really large class of compounds, constituted exclusively by ions, which are liquid at/or near room temperature and present unique physicochemical properties. As first, the ionic nature determines the lack of a measurable vapor pressure and this feature, associated with a high thermal and chemical stability, makes these compounds intrinsically excellent candidates for industrial applications compared to common organic solvents. This is particularly true considering that ILs can 
nicely complement, and even sometimes work better, than organic solvents in a number of industrial processes [1-3].

The Heck reaction represents not only the most extensively investigated Pd-catalyzed process in ILs, but, the related studies practically cover all the development of ILs chemistry up today; they start with the use of onium salts as reaction media, continue with the pyridinium and imidazolium ones to arrive, more recently, to the supported ILs passing through the so-called task-specific ionic liquids, TSILs. This intense activity in this field is probably due to the fact that the Heck coupling is an extremely popular reaction, of industrial interest, which is very versatile but presents a number of wellknown problems and it is generally considered the classical example of palladium catalyzed carboncarbon bond formation process. Heck arylation of electron-deficient olefins have been investigated in ILs mainly to verify the effect of medium on the catalytic system; activity, selectivity and stability of the catalyst under ligand free-conditions, as well as the possibility of catalyst and solvent recovery and recycle have been tested under different conditions. In the case of arylation of electron-rich olefins also the effect on the medium on regioselectivity has been investigated, whereas the possibility of use alternative arylating agents has been rarely evaluated; many of the reported data is related to the reaction of aryl halides (iodides and bromides) with styrenes and acrylates.

\section{Heck Reaction in Common ILs}

Simple palladium salts such as $\mathrm{PdCl}_{2}$ or $\mathrm{Pd}(\mathrm{OAc})_{2}$ in the absence of stabilizing phosphine ligands have been widely used in the Heck reaction in ILs [10-14], and preparatively significant examples have been performed.

In 1984, in a pioneering work Jeffery reported the palladium catalyzed vinylation of organic iodides under solid liquids phase transfer conditions, around room temperature, using tetrabutylammonium chloride [15]. However, the first well-documented application of ILs in the Heck reaction, that is also the first palladium-catalyzed reaction performed in ILs, was reported in 1996 by Kauffmann and coworkers [16]. In particular, they surprisingly found that $\mathrm{Pd}(\mathrm{OAc})_{2}$ and $\mathrm{PdCl}_{2}$ are both appropriate catalyst precursors for Heck reactions without additive ligands (Scheme 1) in $\left[\mathrm{C}_{16} \mathrm{PBu}_{3}\right] \mathrm{Br}$.

Scheme 1. Heck reaction without additive ligands in $\left[\mathrm{C}_{16} \mathrm{PBu}_{3}\right] \mathrm{Br}$.

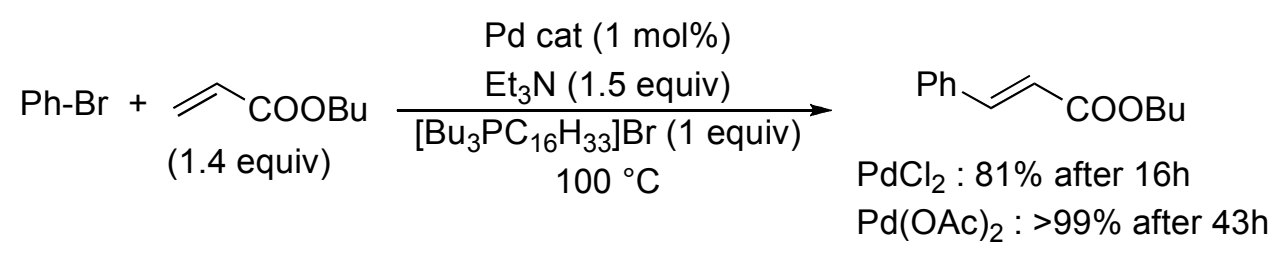

The addition of 1.5 equiv. of $\mathrm{NaOAc}$ when $\mathrm{Pd}(\mathrm{OAc})_{2}$ was used as the catalyst precursor, improved the rate of the coupling, but a concomitant decrease of the selectivity was observed, leading to the formation of $5 \%$ of the $(Z)$-isomer. The precipitation of Pd clusters slowly started after some hours when $\mathrm{PdCl}_{2}$ was used, but with $\mathrm{Pd}(\mathrm{OAc})_{2}$ no precipitation was observed. In this last case the catalyst remained in the melt even at complete conversion of the aryl halide, and after the recover of the product by distillation it resulted active in the following two runs. The authors explained these results by supposing that the phosphonium salt exerted an efficient stabilizing effect on the $\operatorname{Pd}(0)$ species 
obtained in situ by reduction of the $\mathrm{Pd}(\mathrm{II})$ catalyst precursors. The results reported by the group of Kauffmann attracted the attention of several research groups on the important challenge of developing new protocols for a ligand-free Heck reaction. In fact, ligand-free conditions in metal-mediated reactions should be always preferred, especially on large scale productions, not only for saving the cost of the ligand but also because the purifications are simplified if no ligand is present [17].

In 1999 the Earle group reported the use of hexylpyridium chloride, $\left[\mathrm{C}_{6} \mathrm{Py}\right] \mathrm{Cl}$, as solvent in the Heck reaction of iodobenzene with ethyl acrylate using $\mathrm{Pd}(\mathrm{OAc})_{2}$ as the catalyst precursor and $\mathrm{Et}_{3} \mathrm{~N}$ or $\mathrm{NaHCO}_{3}$ as the base (Scheme 2) [18].

Scheme 2. Heck reaction in $\left[\mathrm{C}_{6} \mathrm{Py}\right] \mathrm{Cl}$.

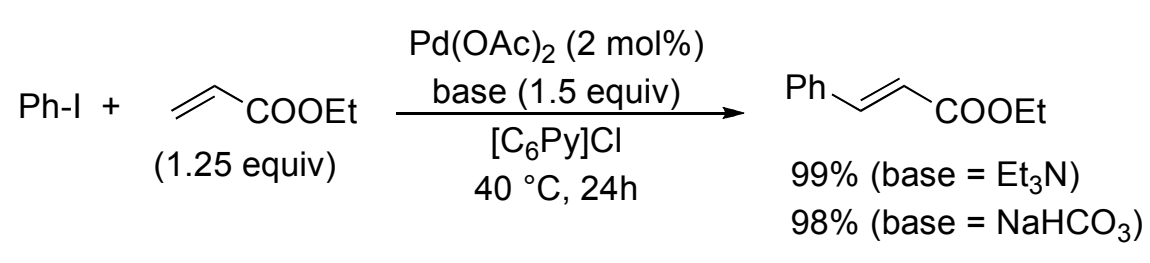

Interestingly, the use of the corresponding salts containing the non-coordinating anions hexafluorophosphate and tetrafluoroborate required longer reaction times and higher temperature to go to completion (Table 1).

Table 1. Influence of the counteranion on the efficiency of the Heck reaction.

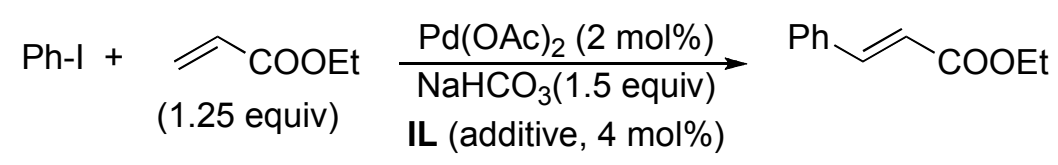

\begin{tabular}{ccccc}
\hline IL & Additive & Reaction temp. $\left({ }^{\circ} \mathbf{C}\right)$ & Reaction time (h) & Yield (\%) \\
\hline$\left[\mathrm{C}_{6} \mathrm{Py}\right]\left[\mathrm{PF}_{6}\right]$ & - & 80 & 72 & 42 \\
{$\left[\mathrm{C}_{6} \mathrm{Py}\right]\left[\mathrm{BF}_{4}\right]$} & & 80 & 72 & 99 \\
{$\left[\mathrm{C}_{6} \mathrm{Py}\right] \mathrm{Cl}$} & $\mathrm{Ph}_{3} \mathrm{P}$ & 40 & 24 & 82 \\
{$\left[\mathrm{C}_{6} \mathrm{Py}\right] \mathrm{Cl}$} & & 100 & 24 & 99 \\
\hline
\end{tabular}

In contrast to the chloride-based systems, the addition of $\mathrm{Ph}_{3} \mathrm{P}$ as ligand also promoted the reaction when an imidazolium-based IL, $[\mathrm{bmim}]\left[\mathrm{PF}_{6}\right]$, was used. The authors explained the experimental results, and in particular the hindering on the efficiency of the reaction of a phosphine, suggesting that in a chloride- (or halide-) reach environment the Heck reaction involves a $\mathrm{Pd}(\mathrm{II}) / \mathrm{Pd}(\mathrm{IV})$ redox cycle, whereas in the case where the phosphine ligand is present a $\operatorname{Pd}(0) / \operatorname{Pd}(\mathrm{II})$ catalyst is operative. However, today a $\mathrm{Pd}(\mathrm{II}) / \mathrm{Pd}(\mathrm{IV})$ mechanism for the Heck reaction is no more accepted. On the contrary, direct NMR measurements and a great deal of experimental data indicate that the Heck reaction proceeds via a $\mathrm{Pd}(0) / \mathrm{Pd}(\mathrm{II})$ catalytic cycle [19]. It is then plausible that the chloride anion contributes to the dissolution of $\operatorname{Pd}(0)$ species which come from the reduction of the $\mathrm{Pd}(\mathrm{II})$ precatalyst better than $\mathrm{BF}_{4}^{-}$or $\mathrm{PF}_{6}^{-}$. 
Related to this work, it must be remarked that benzoic anhydride, in the absence of a base, has been used as a source of the aryl moiety, although higher temperatures and longer times were required to obtain high conversions. The use of hydrophobic ILs gave the possibility to separate products and salt by-products from the catalysts immobilized in IL (for example, in [bmim][PF 6$]$ ), simply by extraction with ethyl ether and water, respectively [18].

Starting from the results reported by Kauffmann, and taking into account the observations made by Jeffery on the activation performed by salt additives and on the ability of stabilizing the catalytically active Pd species [20], Herrmann and co-workers reported in 1999 their results on ligandless Heck reaction performed in $\left[\mathrm{NBu}_{4}\right] \mathrm{Br}$ [21]. As illustrated in Table 2, where the results of these studies have been summarized, $\mathrm{PdCl}_{2}$ resulted highly active in promoting the reaction of olefins with iodobenzene (TON $=10000$, entry 1), bromoarenes (entries 2-9) and also activated chloroarenes (entries 10-12). However, this catalyst precursor is not capable of coupling 4-chloroanisole efficiently (entry 13).

Table 2. Ligand-free Heck arylation in $\left[\mathrm{Bu}_{4} \mathrm{~N}\right] \mathrm{Br}$.[21]

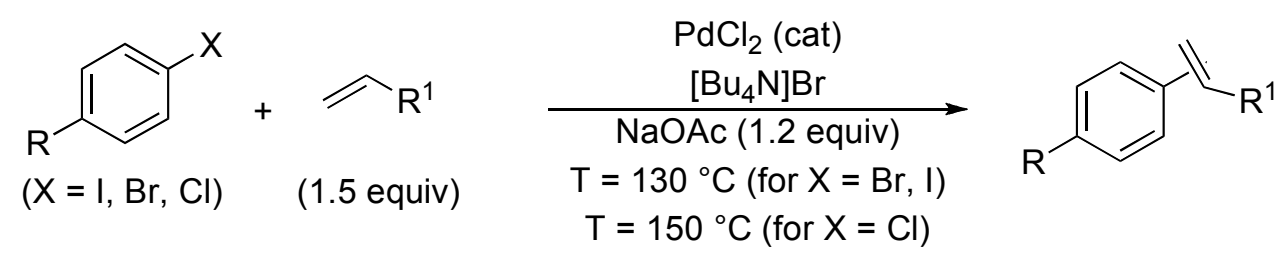

\begin{tabular}{cccccccc}
\hline Entry & $\mathbf{R}$ & $\mathbf{R}^{\mathbf{1}}$ & $\mathbf{X}$ & $\mathbf{P d C l}_{\mathbf{2}}(\mathbf{m o l} \%)$ & $\mathbf{t}(\mathbf{h})$ & Yield GLC (\%) $^{(\mathbf{a})}$ & TON \\
\hline 1 & $\mathrm{Me}$ & $\mathrm{Ph}$ & $\mathrm{I}$ & 0.01 & 14 & 100 & 10000 \\
2 & $\mathrm{COMe}$ & $\mathrm{O}-n-\mathrm{Bu}$ & $\mathrm{Br}$ & 0.2 & 14 & 98 & $490^{(\text {b) }}$ \\
3 & $\mathrm{H}$ & $4-\mathrm{MeOC}_{6} \mathrm{H}_{4}$ & $\mathrm{Br}$ & 0.1 & 14 & 50 & 500 \\
4 & $\mathrm{H}$ & $4-\mathrm{MeC}_{6} \mathrm{H}_{4}$ & $\mathrm{Br}$ & 0.1 & 14 & 68 & 680 \\
5 & $\mathrm{H}$ & $4-\mathrm{CF}_{3} \mathrm{C}_{6} \mathrm{H}_{4}$ & $\mathrm{Br}$ & 1.0 & 14 & 91 & 910 \\
6 & $\mathrm{H}$ & $\mathrm{O}-n-\mathrm{Bu}$ & $\mathrm{Br}$ & 0.2 & 14 & 69 & $345^{(\mathrm{c})}$ \\
7 & $\mathrm{H}$ & $n$-butylmethacrylate & $\mathrm{Br}$ & 1.0 & 14 & 100 & 100 \\
8 & $\mathrm{OMe}$ & $\mathrm{O}-n-\mathrm{Bu}$ & $\mathrm{Br}$ & 0.2 & 13 & 52 & $260^{(\mathrm{d})}$ \\
9 & $\mathrm{OMe}$ & $\mathrm{Ph}$ & $\mathrm{Br}$ & 0.1 & 14 & 69 & 690 \\
10 & $\mathrm{NO} \mathrm{H}_{2}$ & $\mathrm{Ph}$ & $\mathrm{Cl}$ & 0.1 & 19 & 100 & 1000 \\
11 & $\mathrm{COMe}$ & $\mathrm{Ph}$ & $\mathrm{Cl}$ & 0.1 & 14 & 97 & 970 \\
12 & $\mathrm{H}$ & $\mathrm{Ph}$ & $\mathrm{Cl}$ & 5 & 45 & 89 & 18 \\
13 & $\mathrm{OMe}$ & $\mathrm{Ph}$ & $\mathrm{Cl}$ & 3 & 40 & 5 & 2 \\
\hline
\end{tabular}

(a) The yield is referred to the $(E)$. (b) $42 \%(E), 37 \%(Z), 20 \%(1 / 1)$. (c) $17 \%(E), 24 \%(Z), 29 \%(1 / 1)$. (d) $10 \%(E), 14 \%(Z), 27 \%(1 / 1)$.

It is noteworthy that $\mathrm{PdCl}_{2}$ displayed an increased reactivity in $\left[\mathrm{Bu}_{4} \mathrm{~N}\right] \mathrm{Br}$ when compared with DMF, a "classic" solvent for Heck reactions (Scheme 3). 
Scheme 3. Ligand-free Heck arylation in $\left[\mathrm{Bu}_{4} \mathrm{~N}\right] \mathrm{Br}$ and $\mathrm{DMF}$.

\begin{tabular}{|c|c|c|c|c|c|}
\hline \multirow{2}{*}{\multicolumn{2}{|c|}{$\begin{array}{r}\mathrm{Ph}-\mathrm{X}+\mathrm{Ph}_{\mathrm{Ph}} \\
\mathrm{t}=2 \mathrm{~h}, \mathrm{X}=\mathrm{Cl} \text { equiv })\end{array}$}} & \multicolumn{3}{|c|}{$\begin{array}{c}\mathrm{PdCl}_{2}(2 \mathrm{~mol} \%) \\
\mathrm{NaOAc}(1.2 \text { equiv }) \\
150{ }^{\circ} \mathrm{C}\end{array}$} & $P h-\perp_{P r}$ \\
\hline & & \multicolumn{2}{|c|}{$\mathrm{t}=18 \mathrm{~h}, \mathrm{X}=\mathrm{Cl}$} & \multicolumn{2}{|c|}{$\mathrm{t}=2 \mathrm{~h}, \mathrm{X}=\mathrm{Br}$} \\
\hline DMF & {$\left[\mathrm{Bu}_{4} \mathrm{~N}\right] \mathrm{Br}$} & DMF & {$\left[\mathrm{Bu}_{4} \mathrm{~N}\right] \mathrm{Br}$} & DMF & {$\left[\mathrm{Bu}_{4} \mathrm{~N}\right] \mathrm{Br}$} \\
\hline 0 & 7 & 0 & 50 & 16 & 94 \\
\hline
\end{tabular}

The unusual long-term thermal stability of the catalyst in $\left[\mathrm{Bu}_{4} \mathrm{~N}\right] \mathrm{Br}$ most probably accounts to the significant differences observed when the reaction was performed at $150{ }^{\circ} \mathrm{C}$. The catalyst decomposes later in the ammonium salt - if it does at all - than it does in DMF under the same conditions. Indeed, the catalyst seems to be more activated; in fact, $\mathrm{PdCl}_{2}$ runs even about five time faster in $\left[\mathrm{Bu}_{4} \mathrm{~N}\right] \mathrm{Br}$ than in DMF.

The catalyst and the rather expensive solvent could also be recycled. In fact, in the reaction of bromobenzene and styrene using $1 \mathrm{~mol} \% \mathrm{PdCl}_{2}$ and $\mathrm{NaOAc}$ as the base the authors were able to recycle the system several times, nevertheless heavy Pd black formation was observed already during the first run, simply distilling off the reactants and the products in vacuo. It was also possible to filter off the $\mathrm{NaBr}$ and the Pd black precipitate after 8 recycling runs by dissolving the mixture in acetone. After evaporation of the acetone the filtrate can be used again and stilbene was obtained in $60 \%$ yield [22].

The high activity displayed by $\mathrm{PdCl}_{2}$ in $\left[\mathrm{Bu}_{4} \mathrm{~N}\right] \mathrm{Br}$ was ultimately attributed by the authors to the thermal reduction of the $\mathrm{Pd}(\mathrm{II})$ precatalyst to extremely active colloids. However, it is noteworthy that neither $\mathrm{Pd}_{2}(\mathrm{dba})_{3}$ nor preformed $\mathrm{Pd}$ colloids resulted to actively promote the Heck reaction in $\left[\mathrm{Bu}_{4} \mathrm{~N}\right] \mathrm{Br}$, confirming that active species have to form in situ by reduction. The same ammonium salt, in a mixture with $\left[\mathrm{Bu}_{4} \mathrm{~N}\right] \mathrm{OAc}$, was employed three years later by Cacchi and co-workers in an efficient stereoselective synthesis of $(E)$ - and (Z)-3,3-diarylacrylates [23].

In particular, the Pd-catalyzed reaction of neutral, slightly electron-rich and slightly electron-poor aryl iodides with methyl cinnamate in a molten $\left[\mathrm{Bu}_{4} \mathrm{~N}\right] \mathrm{OAc} /\left[\mathrm{Bu}{ }_{4} \mathrm{~N}\right] \mathrm{Br}(2: 1.5)$ mixture provided with high stereoselectivity $(E)-3,3$-diarylacrylates $(E / Z=98 / 2$ to $>99 / 1)$ (Scheme 4). Phosphine-free $\mathrm{Pd}(\mathrm{OAc})_{2}$ was employed as the catalyst precursor.

Scheme 4. Heck arylation in $\left[\mathrm{Bu}_{4} \mathrm{~N}\right] \mathrm{OAc} /\left[\mathrm{Bu}_{4} \mathrm{~N}\right] \mathrm{Br}$.

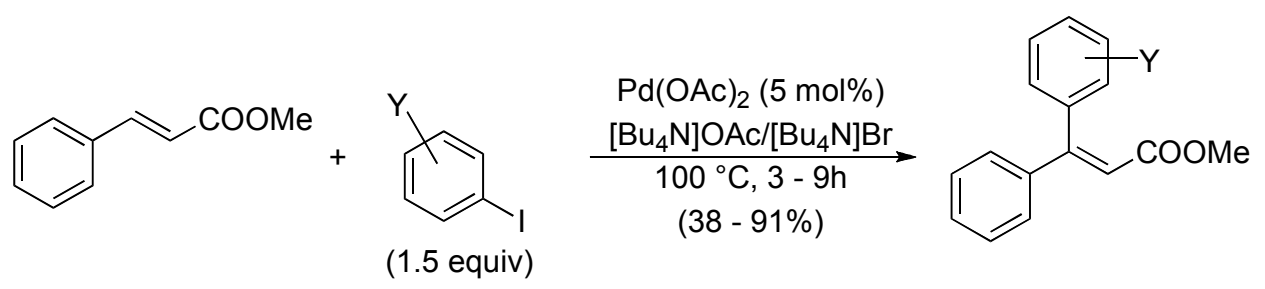

$(\mathrm{Y}=$ 4-EtOOC, 4-Cl, 4-MeO, 3-Me, 3-MeCONH, 3-MeO, 4-F)

Moreover, the reaction of a variety of methyl 3-arylacrylates with iodobenzene under the same reaction conditions afforded selectively the corresponding $(Z)$-isomers $(E / Z=4 / 96$ to $<1 />99)$ (Scheme $5)$. It was also observed that the catalyst system might be recycled without any loss of activity. 
Scheme 5. Heck arylation of methyl 3-arylacrylates with iodobenzene.

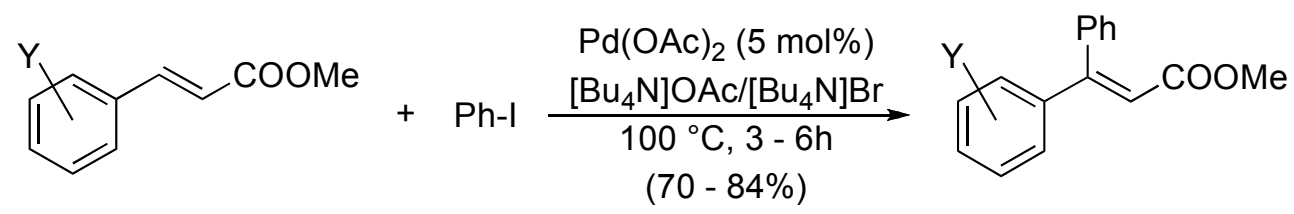

$(\mathrm{Y}=4-\mathrm{EtOOC}, 4-\mathrm{Cl}$, 4-MeO, 4-Me, 3-Me, 4-MeCONH, 4-NO 2 , 3-MeO, 4-F)

The authors, in order to justify the observed elevated stereoselectivity, attributed to the acetate anion a key role; in particular, they supposed that this anion could favour the irreversible displacement of $\mathrm{Pd}$ from $\sigma-\mathrm{Pd}$ adducts thus suppressing any possible isomerization mechanism. They also attributed the high reactivity of $\mathrm{Pd}(\mathrm{OAc})_{2}$ in the used molten salt mixture to the formation of palladium nanoparticles stabilized by the ammonium salts.

A similar stabilization of the active Pd catalytic species was invoked by Muzart and co-workers, who employed $\mathrm{NaHCO}_{3}$ as the base and $\mathrm{PdCl}_{2}$ as the catalyst precursor in a Heck arylation of allylic alcohols in $\left[\mathrm{Bu}_{4} \mathrm{~N}\right] \mathrm{Br}$, affording $\beta$-arylated carbonyl compounds (Scheme 6) [24].

Scheme 6. Heck arylation of allylic alcohols in $\left[\mathrm{Bu}_{4} \mathrm{~N}\right] \mathrm{Br}$.

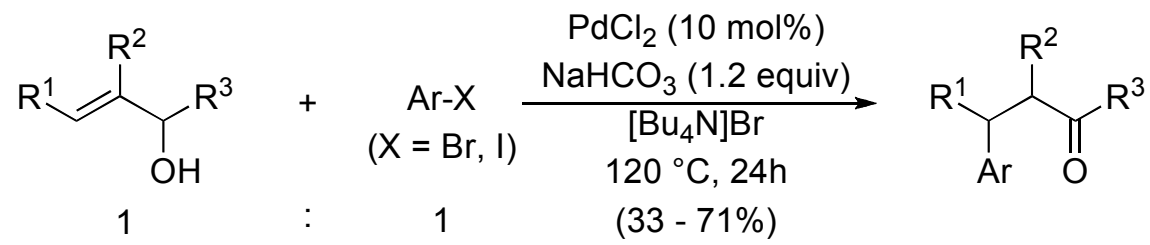

This protocol, which let possible to recycle the active catalyst up to four times, was also applied to a one-step synthesis of the nonsteroidal antiinflammatory drug nabumethone (Scheme 7) [24].

Scheme 7. Synthesis of nabumethone.

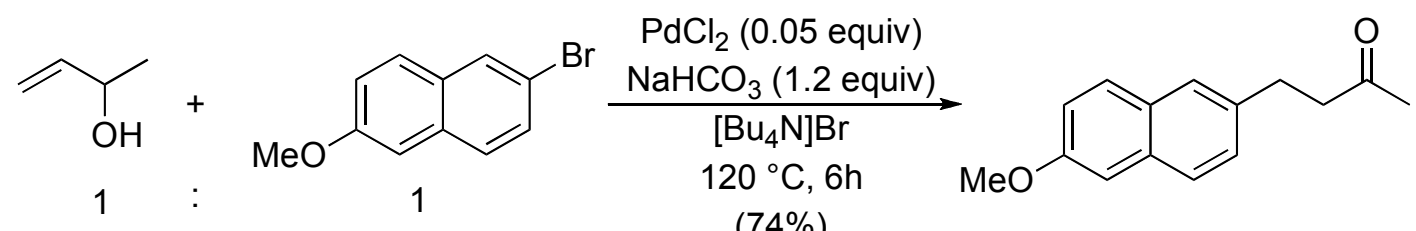

$(74 \%)$

During the past decade, in a series of important papers [25-27] Calo' et al. have evidenced the superiority of tetraalkylammonium halides over common pyridinium and imidazolium salts in terms of catalysts stability, reaction rates and regio- and stereoselectivity in Pd nanoparticles catalyzed coupling reactions. Bromoarenes were coupled with less reactive 1,2-disubstituted alkenes, such as transcinnamates, in a stereospecific manner under ligand-free conditions in 1:1.5 molar mixtures of tetrabutylammonium bromide and tetrabutylammonium acetate, TBAB-TBAA (Scheme 8) [26]. The observed stereoselectivity was ascribed not only to a better solubility of TBAA in TBAB, but also to an intramolecular neutralization of $\mathrm{PdH}$, still ligated to the olefin, by an acetate ion in the metal coordination shell through a five-membered transition state. 
Scheme 8. Heck arylation of ethyl trans-cynnamate.

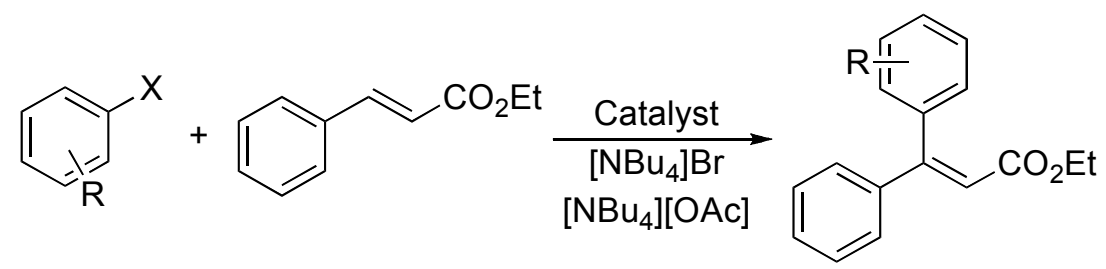

The absence of acetate in the coordination shell would allow the $\mathrm{PdH}$ isomerization, leading to a thermodynamic mixture of isomeric olefins. This palladium nanoparticles-catalyzed Heck arylation was extended to butyl methacrylate and $\alpha$-methylstyrene. In this case, however, a 3:1 mixture of regioisomers was obtained in favour of the terminal olefins, together with variable amounts of doublearylated products [27].

In this contest, recently Nacci et al. have recently reported [28] a general method for coupling of aryl chlorides, including deactivated and electron-rich aryl chlorides, using ligand-free $\mathrm{Pd}(\mathrm{OAc})_{2}$ in the molten mixture of tetraalkylammonium ionic liquids (TBAB-TBAA) under aerobic and relatively mild conditions (Scheme 9). Interestingly, using this system it was possible to couple 1-bromo-4chlorobenzene with two different olefins in a one-pot sequential manner by activating the $\mathrm{C}$ - $\mathrm{Br}$ and $\mathrm{C}$ $\mathrm{Cl}$ bonds on the aromatic ring at two different temperatures of 100 and $120{ }^{\circ} \mathrm{C}$. Unsymmetrical substituted arenes were produced with high reaction rates and high overall yield.

Scheme 9. One-pot sequential coupling of 1-bromo-4-chlorobenzene.

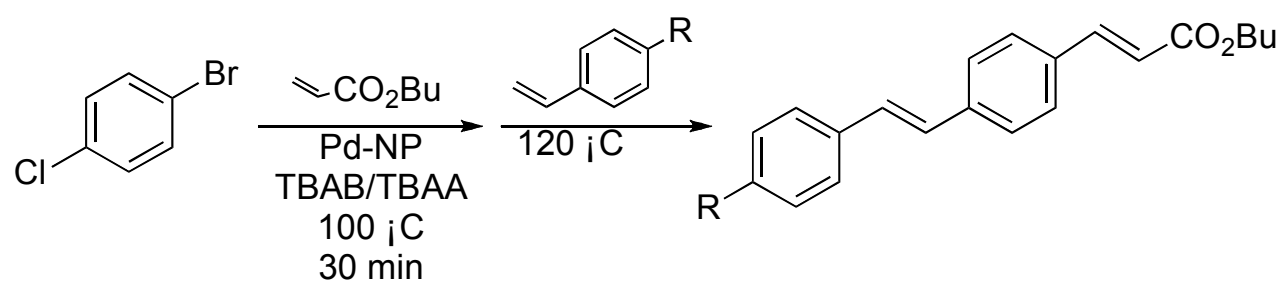

An extensive investigation on Pd-catalyzed Heck reactions in imidazolium based ILs has been performed by the research group of Xiao. In 2000, they published [29] a detailed study on reaction of iodobenzene with styrene and acrylates catalyzed by $\mathrm{Pd}(\mathrm{OAc})_{2}$, showing for the first time that the imidazolium cation can react with a catalyst precursor to form $N$-heterocyclic carbene complexes via deprotonation in the imidazolium-based ionic liquids under catalytic conditions, and that the carbene complexes so generated are active for $\mathrm{C}-\mathrm{C}$ bond coupling reactions. Subsequently, they focused on the palladium catalyzed arylation of the electron-rich olefins, such as butyl vinyl ether in [bmim] $\left[\mathrm{BF}_{4}\right]$, using aryl iodides and bromides as the arylating agents. The results of these studies, reviewed in 2008 [30], showed that imidazolium ILs in combination with the readily available $\mathrm{Pd}(\mathrm{OAc})_{2}$ and 1,3-bis(diphenylphosphino)propane (DPPP) form an excellent catalytic system, in which highly regioselective and yielding arylation of electron reach olefins can be performed with a wide range of aryl halides with no need for any halide scavengers (Scheme 10). 
Scheme 10. Highly regioselective arylation of electron rich olefins.

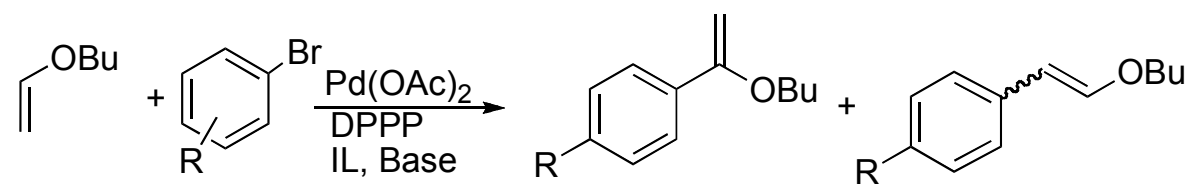

Generally, the arylation gives only the branched olefins; the unique stereocontrol has been attributed to the ionic environment, which alters the reaction mechanism favoring the ionic pathway. It is however noteworthy that for this kind of reactions little conversions $(<1 \%)$ were observed [31] in $[\mathrm{bmim}] \mathrm{Br}$ and $[\mathrm{bmim}] \mathrm{Cl}$ and these results were attributed to the coordination of halides with palladium and/or the formation of inactive imidazolium carbene complexes of Pd. The inhibitory effect of bromide on this reaction has been subsequently more extensively investigated [32] by the same authors, who on the basis of the dramatic decreases in the arylation rate with increasing bromide concentration, hypothesized the presence of an equilibrium (eq. 1) before the rate determining step.

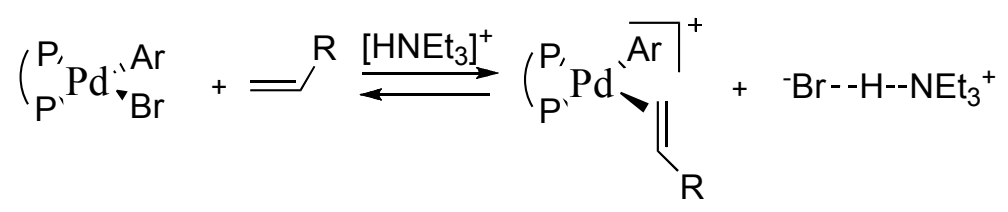

$\mathrm{HBr}$, generated from each arylation, must be effectively scavengered by the $\mathrm{NEt}_{3}$, which may be able to trap also the bromide anions by hydrogen bonding between $\left[\mathrm{HNEt}_{3}\right]^{+}$and $\mathrm{Br}^{-}$. A remarkable accelerating effect exerted by the potential hydrogen bond donor $\left[\mathrm{HNEt}_{3}\right]^{+}$was evidenced in the same paper.

In conclusion, whereas halides $\left(\left[\mathrm{NBu}_{4}\right] \mathrm{Cl}\right)$ are able to accelerate the Heck reaction employing palladium catalysts containing monodentate olefins or no ligands, they have an inhibitory effect on Pddppp catalyzed reactions. To a different mechanism, molecular in the first case and ionic in the second one, was attributed the different behavior (for a detailed discussion see below).

Despite of the extensive work performed on Heck reactions in the last ten years, it is however noteworthy that only few data have been reported on the intramolecular process. The sole paper on this topic evidenced that substituted benzofurans can be obtained [33] in modest to good yields by palladium-catalysed intramolecular Heck reaction in $[\mathrm{bmim}]\left[\mathrm{BF}_{4}\right](\mathrm{Scheme} 11)$. In general, the yields of the substrates with a substituent on the aryl group were lower, although the character of the substituent was not able to affect significantly the reaction yield. The catalyst in the IL phase could be re-used by the addition of another portion of substrate, $\mathrm{Bu}_{3} \mathrm{~N}$ and $\mathrm{HCO}_{2} \mathrm{NH}_{4}$; the catalytic activity varied from 71 to $57 \%$ after four cycles.

Scheme 11. Intramolecular Heck reaction.

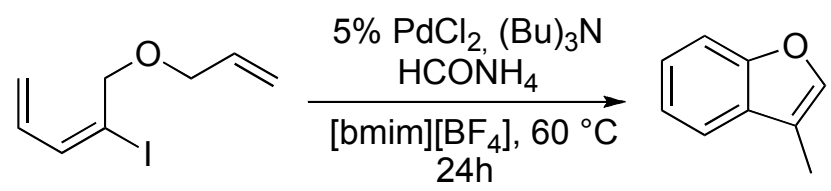


Finally, it must be remarked that although generally aryl halides have been used in most of the investigated reaction in ILs, in 2004 Kabalka et al. reported [34] the palladium catalysed reaction of methyl acrylate and methyl acrylonitrile with arenediazonium salts in $[\mathrm{bmim}]\left[\mathrm{PF}_{6}\right]$. The reactions could be performed at room temperature for methyl acrylate and at $50{ }^{\circ} \mathrm{C}$ for acrylonitrile in the absence of base and in relatively short reaction times (Scheme 12). The catalytic system was recycled at least four times without loss of activity, although electron-rich olefins did not react and styrenes produced dimerisation products.

Scheme 12. Heck reaction with arenediazonium salts.

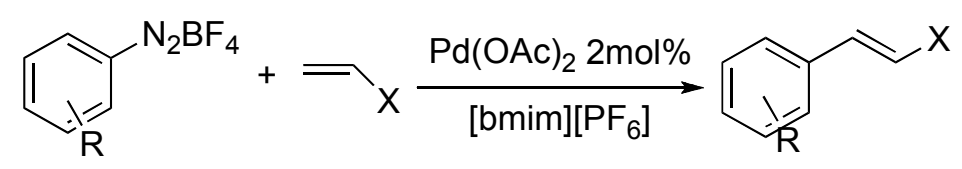

\section{Task-Specific Ionic Liquids (TSILs) in the Heck Reaction}

On the base of the data reported in the previous section it is possible to conclude that the Heck reaction based on the use of ILs is clearly advantageous from the point of view of product separation and re-use of the catalytic system. In addition, most of the reactions can be performed in the absence of added phosphorous containing ligands and, selecting ionic liquid and reaction conditions, it is possible to use also aryl bromides and chlorides or benzoic anhydrides. However, common ILs still have a tendency to leach dissolved catalysts into the co-solvent used to extract the product(s). To avoid metal catalysts leaching out of the IL system, significant efforts have been made to enhance the solubility of the catalysts in ILs and practically two approaches have been followed: i) functional groups able to coordinate with metal centers have been inserted into the ILs, ii) imidazolium/pyridinium tags have been introduced into a metal complex.

In this context, in 2004 Shreeve et al. reported [35] the synthesis of the monoquaternary product arising from the reaction of 2,2'-diimidazole with iodobutane and the application of the obtained IL as solvent and ligand for the Heck reaction. The new palladium complex, reported in Scheme 13, was isolated by adding $\mathrm{PdCl}_{2}$ to this ionic liquid in methanol. The same 2-imidazole functionalized IL was used for the Heck coupling of iodobenzene with methyl acrylate in the presence of $\mathrm{PdCl}_{2}(2 \mathrm{~mol} \%)$ and $\mathrm{Na}_{2} \mathrm{CO}_{3}$ as a base. After product recovery (92\% yield) the system was washed with water and reused another four times without significant activity loss. The recovered system was used also with the non-reactive chlorobenzene, leading to the same product in $74 \%$ yield after two runs.

Scheme 13. Palladium complex from 2-imidazole fuctionalized ILs.

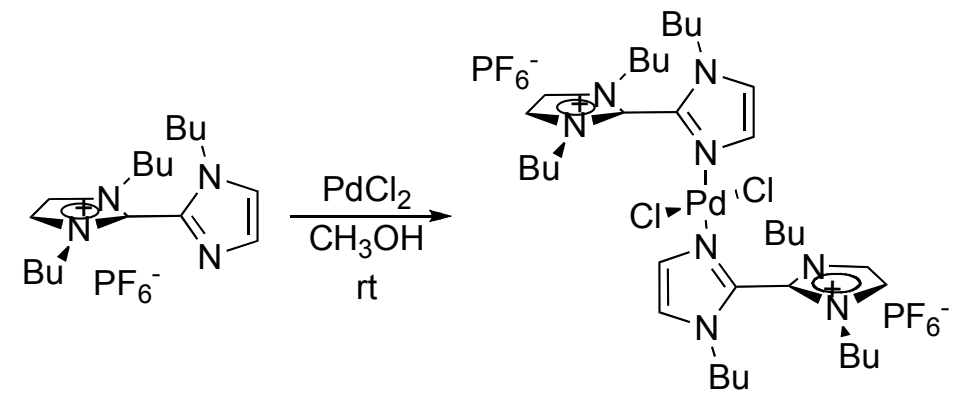


An analogous functionalized palladium(II) complex was obtained by reaction 1-butyl-2-(2-pyridyl)3-methylimidazolium bistriflimide with $\mathrm{PdCl}_{2}$ in methanol. The coupling reaction of iodobenzene with butyl acrylate in the corresponding IL, 1-butyl-2-(2-pyridyl)-3-methylimidazolium bistriflimide, or in the analogous 1-butyl-2-(phenyl)-3-methylimidazolium bistriflimide could be performed successfully 10 times without detectable loss of catalytic activity (Scheme 14).

Scheme 14. Palladium complex from 2-(2-pyridyl) fuctionalized ILs.

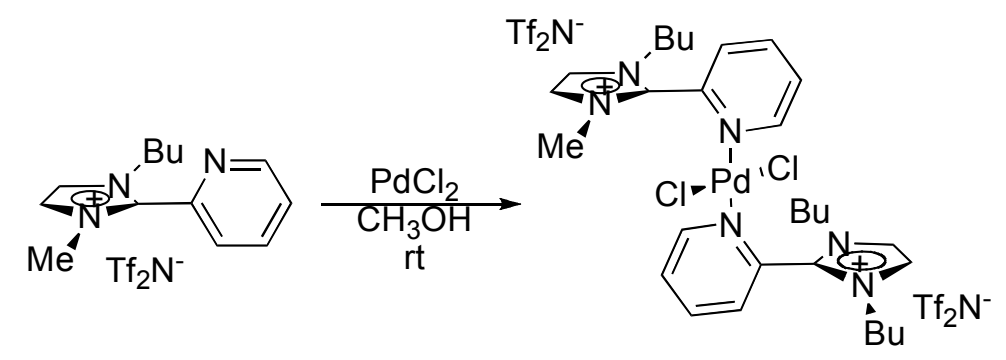

However, when the Heck reaction was carried out using $\mathrm{PdCl}_{2}$ under similar conditions, the formation of palladium black was evidenced and after two cycles the system became practically inactive. Moreover, whereas no appreciable difference in yields between activated and deactivated aryl iodides was found, the electronic nature of aryl bromides had a clear effect on the coupling reaction.

But the functionalization of the imidazolium ring not necessarily have to involve the $\mathrm{C}(2)$ imidazolium carbon. Substituents able to interact with palladium(II) have been introduced also on the imidazolium nitrogen. Pyrazolyl-functionalized 2-methylimidazolium based ILs have been therefore synthesized and the activity and recyclability of the palladium complexes have been evaluated [36] (Figure 1).

Figure 1. Palladium complex from N-pyrazolyl 2-methyl imidazolium based IL.

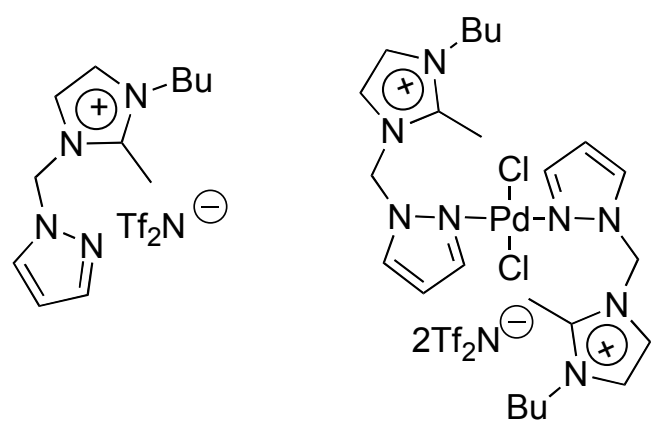

Initially, the Heck reaction was performed using as catalyst the functionalized palladium complex dissolved in the pyrazolyl-functionalized IL. However, interestingly, this catalyst could be used also in a unfunctionalized IL (1-butyl-2,3-dimethylimidazolium bistriflimide) obtaining at the 9th recycle a complete conversion of iodobenzene. The efficiency of the process was attributed to the presence on the catalyst of a pendant 2-methylimidazolium tag which is similar to the unfunctionalized IL and favour immobilization. Of course, when the Heck reaction was examined using $\mathrm{PdCl}_{2}$ as the catalyst precursor in the pyrazolyl-functionalyzed IL under identical conditions similar results were obtained. In this reaction, reactivity decreased using bromobenzenes whereas only traces of the product were obtained with 4-chlorobenzene. 
Starting from N-alkylimidazoles another series of pyrazolyl-functionalized imidazolium based ILs was subsequently synthesized and characterized [37]. Through a (carbene)silver complex, a palladium complex was prepared, isolated and characterized. In this case, as a consequence of the absence of the methyl group at $\mathrm{C}(2)$ on imidazolium ring, the functionalized IL acted as a chelating ligand coordinating the palladium(II) center through its carbene carbon atom and the pyrazolyl nitrogen atom to give a six-membered metallacycle with boat-like conformation (Figure 2).

Figure 2. Palladium complex from N-pyrazolyl imidazolium based IL.
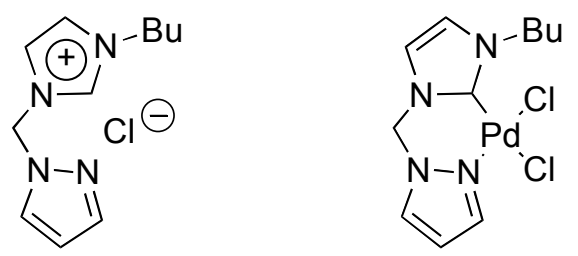

The catalytic activity as a pre-catalyst was investigated in the corresponding IL using the above reported procedure. Aryl halides gave with butyl acrylate the expected product in $>90 \%$ yield independently of the substituents on the phenyl ring. No detectable loss of catalytic activity was observed after five recycles. Contemporaneously, also the activity of a hemilabile pyrazolylfunctionalized $\mathrm{N}$-heterocyclic carbene complex of $\mathrm{Pd}(\mathrm{II})$ in $[\mathrm{bmim}]\left[\mathrm{PF}_{6}\right]$ was evaluated by the same group [38]. The catalyst could be recovered and recycled at least three times without significant loss of activity (Figure 3).

Figure 3. Palladium complex from N-pyrazolyl-N-aryl imidazolium based IL.

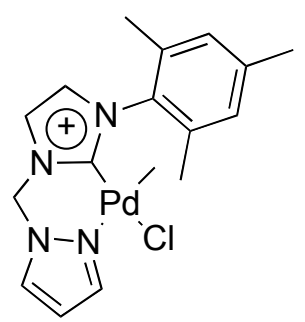

On the other hand, considering that some chelate or pincer N-heterocyclic Pd-carbene complexes exhibit high catalytic activity for Heck reactions [39], the application of an IL containing a pincer dication substituted with two alkyl chains has been investigated in the Heck reaction of aryl halides with butyl acrylate at $120^{\circ} \mathrm{C}$ [40] by Shreeve et al. (Scheme 15). Iodobenzene was found to have the highest reactivity, giving trans-butylcinnamate in $92 \%$ yield using both $\mathrm{PdCl}_{2}$ or the isolated palladium complex as catalyst and $\mathrm{NaOAc}$ as base, whereas bromobenzene resulted in $71 \%$ yield and chlorobenzene was practically unreactive ( $3 \%$ yield). In this case, the recovered IL could be reused three-times without significant loss of activity. 
Scheme 15. Palladium complex from an IL containing a pincer dication.

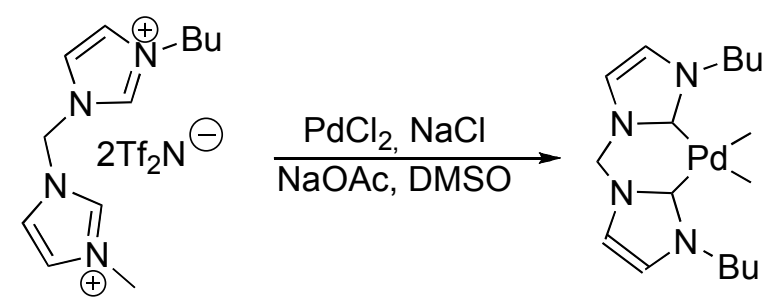

Since the introduction of a third nitrogen atom on the five member heteroaromatic system could increase the acidity of the $\mathrm{C}-2$ position favoring $\mathrm{Pd}$-carbene complex formation, unsymmetrical dicationic salts incorporating imidazolium and triazolium functionalities were also synthesized and tested [41].

It is noteworthy that, instead of a chelating palladium(II) dicarbene complex, the reaction with $\mathrm{Pd}(\mathrm{OAc})_{2}$ in DMSO gave a dinuclear complex, which analogously to the above reported complexes could be used as pre-catalyst in the Heck reaction (Scheme 16). Comparable results were obtained using the same procedure.

Scheme 16. Synthesis of dinuclear palladium complex.

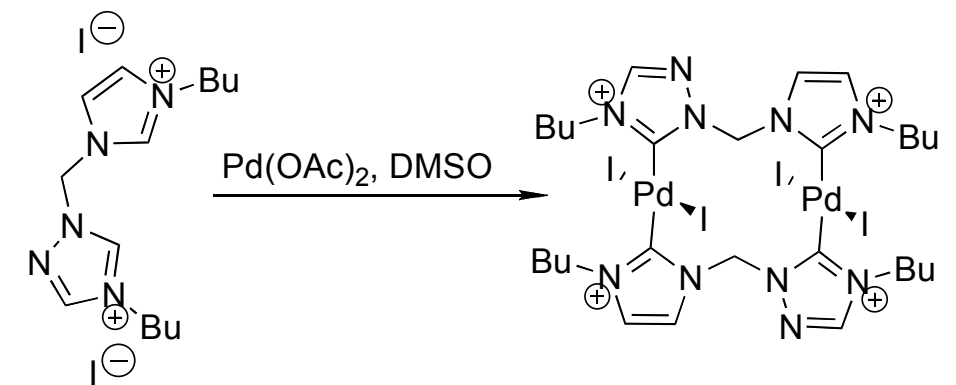

Contemporaneously, the strategy to introduce specific functional groups on the alkyl chain of imidazolium cation to increase the catalyst immobilization has been followed by other research groups.

In this contest, it has been shown [42] that the use of an imidazolium based phosphinite IL (Figure 4) as solvent and as ligand in the coupling reaction of aryl halides (including chlorobenzene) with styrene and butyl acrylate allows the synthesis of the expected product in high yield (generally, around $90 \%$ also for $\mathrm{ArCl}$ ) assuring also a high recyclability (six runs without losing its efficiency). Although the crystal structure of the catalyst was not reported, the formation of a carbene-type complex was excluded on the basis of the ${ }^{1} \mathrm{H}$ NMR spectrum, and a ML2 complex was hypothesized.

Figure 4. Imidazolium based phosphinite IL.<smiles>CC(C[n+]1ccn(C)c1)OP(=O)(O)c1ccccc1</smiles>

Significant results have been obtained also by Dyson et al. introducing a nitrile group on the alkyl chain(s) of pyridinium and imidazolium based-ILs (Figure 5) [43-45]. 
Figure 5. Nitrile functionalized ILs.<smiles>[R]c1n(C)cc[n+]1CCCC#N</smiles><smiles></smiles>

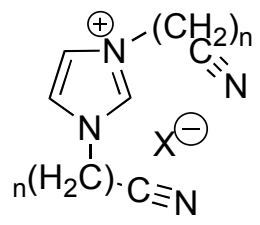

Nitrile-functionalized ILs have been used with success in several palladium catalyzed reactions, including the Heck process and their usefulness became apparent upon catalyst recycling; while in conventional ILs activity rapidly decreased to zero, in nitrile-functionalized ILs little change was observed after several recycles. Functionalization of the alkyl chain facilitates the solubility of the Pd(II) precatalyst via weak coordination of the nitrile groups to the palladium center, as evidenced through IR measurements (Figure 6). Moreover, when palladium nanoparticles are involved nitrile group may form a protective sheath around the nanoparticles, preventing aggregation.

Figure 6. Coordination of the nitrile group to the palladium center

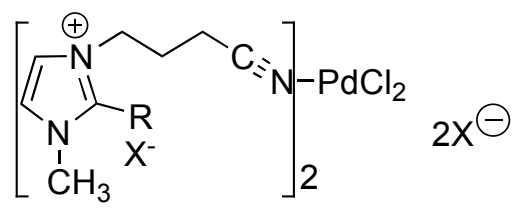

It is noteworthy that, at variance with other palladium catalyzed reactions, reuse of the IL system in the Heck reaction was not very encouraging, due to observed progressive loss of activity. The decrease in reactivity of the catalyst could be however ascribed to the consumption of the base; the addition of 1 equiv of cholinium acetate after the fourth cycle restored the reactivity of the system.

To overcome the problems arising from the depletion of the base during the recycles, more recently basic IL have been employed as both solvents and proton scavenger in Heck coupling reactions. The first example, reported [46] by Shreeve et al., evidenced that IL bearing tertiary aliphatic amines are effective media for the Heck reactions (Figure 7).

Figure 7. Basic ionic liquid cations.
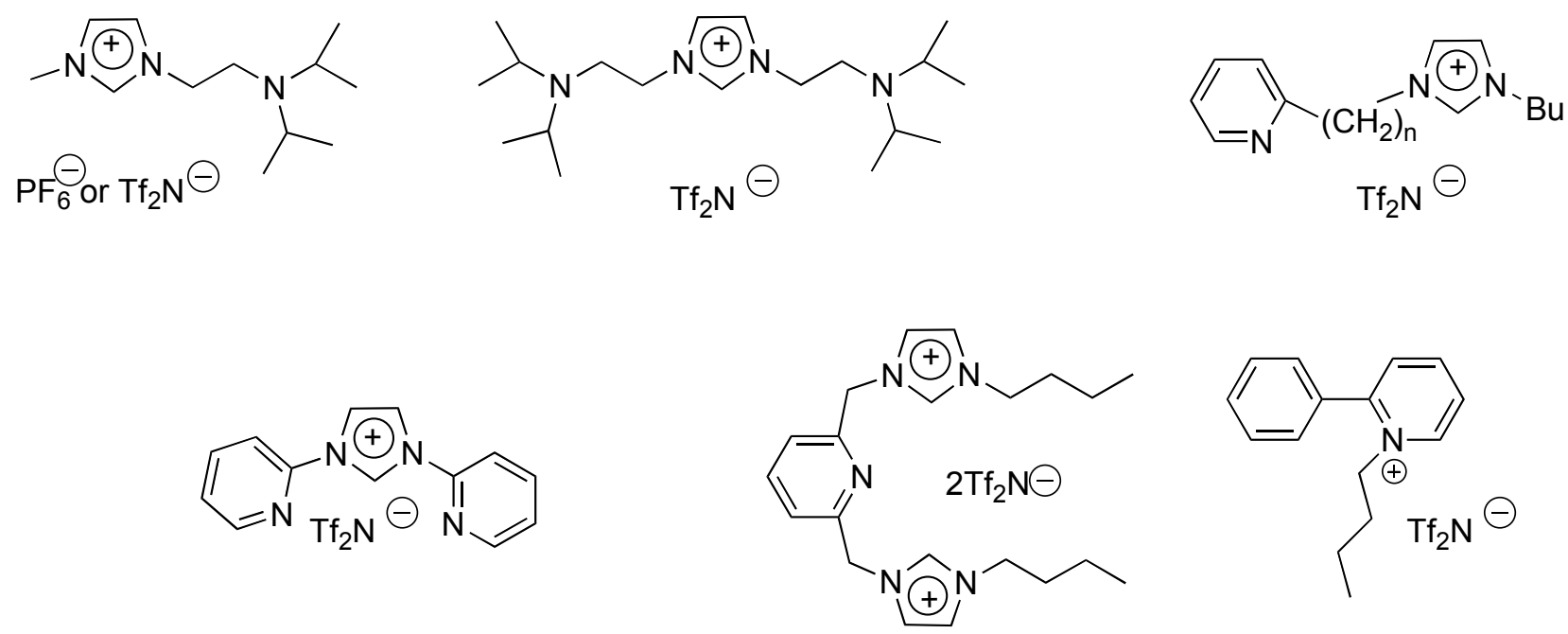
Under reflux conditions, iodobenzene reacted with butyl acrylate to give the cinnamic ester in $100 \%$ yield. The catalytic system could be reused simply by washing with $\mathrm{NaHCO}_{3}$; after five recycles no activity loss was observed. Also in this case the formation of palladium nanoparticles was observed; all attempts to synthesize carbene-palladium complexes resulted in stable palladium colloids. The hypothesis that the tertiary amine might act as reducing agents in the redox process, leading to the formation of nanoparticles, was advanced.

Subsequently, 1,4-diazabicyclo[2,2,2] octane (dabco)-based ILs (Figure 8) having as counteranion the basic dicyanamide or tetrafluoroborate have also been tested in the Heck reaction [47]. Although after two hours the yields of the recovered product for the model reaction (iodobenzene-ethyl acrylate) were lower than in the comparative reaction performed in $[\mathrm{bmim}]\left[\mathrm{BF}_{4}\right]$, the dabco-based ILs could be reused without re-addition of base and reducing agent.

Figure 8. 1,4-Diazabicyclo[2,2,2]octane (dabco)-based ILs.

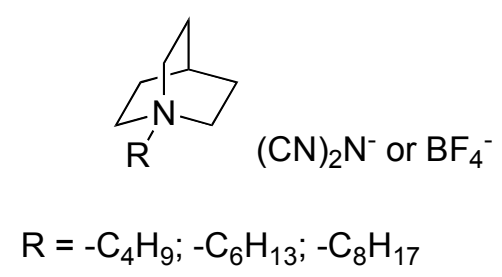

Finally, also hydroxyl or diol functionalized ILs (Figure 9) have been employed has reaction media and catalyst ligands in the Heck reaction. In 2003, Handy et al. prepared a new class of hydroxymethyl substituted imidazolium based ILs using fructose as the starting material [48.].

Figure 9. Hydroxyl functionalized ILs.

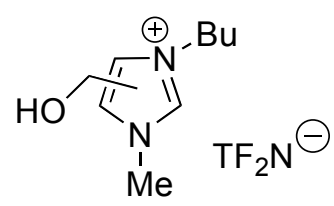

The ionic liquid having bistriflimide as counteranion was employed as solvent for the model Heck reactions of methyl acrylate with simple aryl iodides in the presence of $\operatorname{Pd}(\mathrm{OAc})_{2}$. The coupling products were isolated in almost quantitative yields simply by extracting the crude mixtures with cyclohexane. Moreover, the solvent and catalyst were recycled 4-5 times without affecting the efficiency of the reaction. Also in this medium, however, the Heck coupling was slower than those performed in the standard, non-protic [bmim] series ionic liquids, although not at a great extent. An interesting accelerating effect of catalytic amounts of certain halide ions on the coupling of iodobenzene and methyl acrylate was observed.

More recently, a series of imidazolium based ILs N-functionalized with a 2,3-dihydroxypropyl group (Figure 10) has been used as ligands and solvents for palladium(II)-catalyzed reactions; these compounds present, besides the N-heterocyclic donor moiety arising from the imidazolium skeleton, the ethylene glycol group able to act as an excellent chelating ligand [49]. 
Figure 10. 2,3-Dihydroxyl functionalized ILs.

The Heck coupling of iodobenzene and ethyl acrylate in glycerylimidazolium-based ionic liquids at $100{ }^{\circ} \mathrm{C}$ has been performed in the presence of $5 \mathrm{~mol}-\% \mathrm{PdCl}_{2}$ as the catalyst precursor and $\mathrm{AcONa}(1.1$ equiv) as the base. Although reuse of the IL systems was not very encouraging, due to the progressive loss of activity, a high reaction rate was observed in particular in 1-glycerol-3-octylimidazolium chloride, [GLYOCTIM]Cl. The reaction yields increased on increasing the alkyl chain on cation $([\mathrm{GLYOCTIM}] \mathrm{Cl}>[$ GLYBIM]Cl $>$ [GLYMIM]Cl, and [GLYOCTIM]Br > [GLYBIM]Br) and were affected by anion nature and by the presence of a methyl group at $\mathrm{C}(2)$. The very low yield obtained by using 1,2-dimethyl-3-glycerylimidazolium chloride as solvent suggested that imidazolium carbenes, formed by reaction of the base with the acidic $\mathrm{C}(2)-\mathrm{H}$ bond of the $\left[\mathrm{GLYIM}^{+}\right]$cations, might be actively implicated in these reactions (vide infra). Since the formation of carbenes in imidazoliumbased ILs should be favoured by the basicity of the counteranion [50], the involvement of these species is also in agreement with the anion effect: bromides give lower conversions than chlorides and practically no reaction was observed in [GLYBIM]OMs.

Finally, 1-glycerol-3-methylimidazolium hexafluorophosphate has been successfully used [51,52] also as the active and recyclable catalytic system in the reaction of aryl bromides with methyl ethyl acrylate under aerobic condition in DMF.

Recently, a novel IL able to act as base, ligand and activator (Figure 11) has been synthesized by Wang et al. [53] The olefination process of alkenes (styrene, acrylates and acrylonitrile) with activated and deactivated iodo, bromo and chloroarenes has generated the corresponding products in good to excellent yields in 4-(dihydroxyethyl)aminobutylammonium bromide). Transmission electron microscopy (TEM) has evidenced the formation of particles having an average diameter of $c a .4 \mathrm{~nm}$ suggesting that the ethanolamine functionalized IL are able to stabilize palladium colloids. It is noteworthy that the system is characterized by a high recyclability; palladium and IL were recycled six times with no loss of their activity and the inductively coupled plasma (ICP) analyses of the extracted organic solvents indicated that $\mathrm{Pd}$ content was $<0.2 \mathrm{ppm}$. 
Figure 11. Multifunctionalized IL.

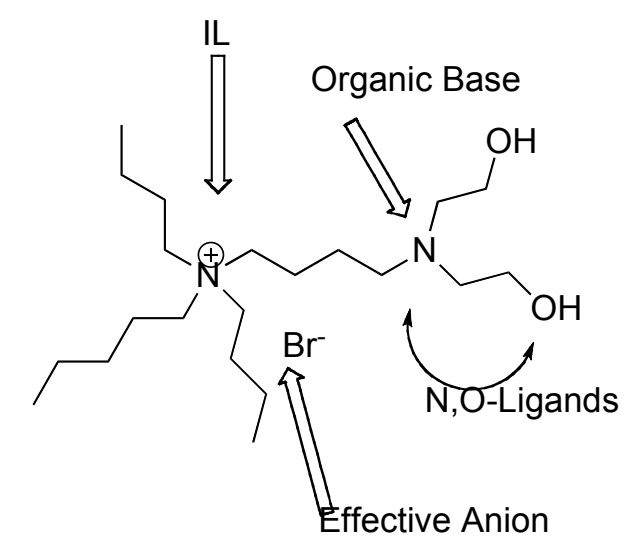

An alternative approach to the use of multifunctionalized ILs may be the use of mixtures of differently substituted ILs which can exert the functions of ligand, base and reaction medium as one unit. In this contest, the ternary mixture of 1-butyl-2-diphenylphosphino-3-methylimidazolium hexafluorophosphate, $\quad[\mathrm{bdppmim}]\left[\mathrm{PF}_{6}\right], \quad$ 1-(2-piperid-1-yl-ethyl)-3-methylimidazolium hexafluorophosphate, [pemim] $\left.\mathrm{PF}_{6}\right]$ and 1-butyl-3-methylimidazolium hexafluorophosphate, [bmim] $\left[\mathrm{PF}_{6}\right]$ represents an efficient and recyclable system for the $\mathrm{PdCl}_{2}$ catalyzed coupling of aryl halides (including hindered and electron-rich aryl iodide and activated aryl bromides) with ethyl acrylate (Figure 12) [54].

Figure 12. Mixture of monofunctionalized ILs.<smiles></smiles><smiles>Cn1cc[n+](CCN2CCCCC2)c1</smiles><smiles>CCCC[n+]1ccn(C)c1</smiles>

Experiments performed using the single ILs or their binary mixtures evidence a synergistic effect when used as one unit: due to the presence of more coordinating sites the palladium catalyst combined the advantageous activity and stability of N,P-containing ligand coordinated Pd complexes and Pdcarbene complexes, although the exact nature of the species present in solution was unknown. Furthermore, the strong hydrophobicity of the resulting system allowed the recovery of [pemim] $\left[\mathrm{PF}_{6}\right]$ during the washing phase between two subsequent cycles and the recycling uses of palladium catalyst.

More recently, the catalytic activity of 1-butyl-2-diphenylphosphino-3-methylimidazolium hexafluorophosphate, $\quad$ bdppmim $]\left[\mathrm{PF}_{6}\right], \quad$ or $\quad$ 1-(2-piperid-1-yl-ethyl)-3-methylimidazolium hexafluorophosphate, $[$ pemim] $]\left[\mathrm{PF}_{6}\right]$ in the model Heck reaction of aryl halides with methyl or ethyl acrylates in $[\mathrm{bmim}]\left[\mathrm{PF}_{6}\right]$ has been compared [55] with that of a hybrid P,N ligand functionalized IL, 1-(2piperid-1-yl-ethyl)-2-diphenylphosphino-3-methylimidazolium hexafluorophosphate, [pedppmim][ $\left.\mathrm{PF}_{6}\right]$, combining the structural peculiarities of the other two ligands in a sole molecule. In this case an organic base was always added. 
Figure 13. Mixture of monofunctionalized ILs.
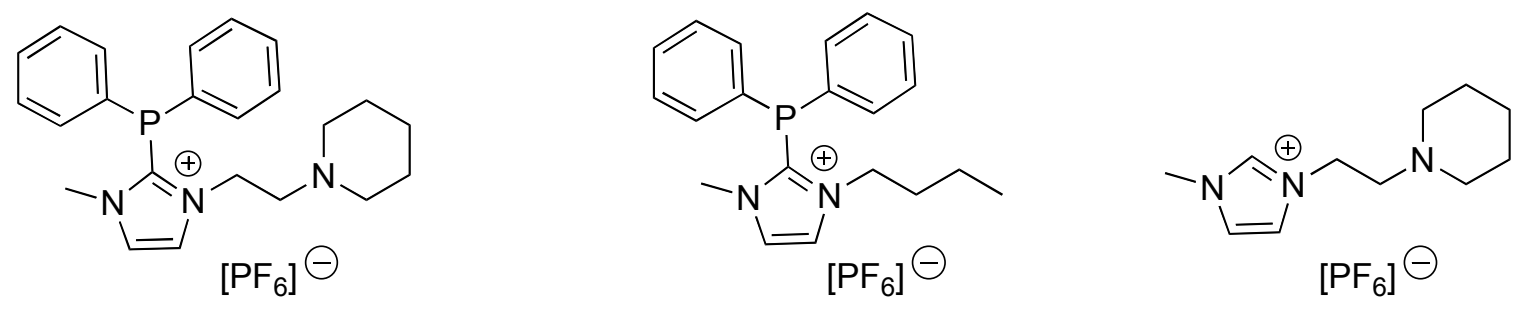

With the involvement of the hybrid $\mathrm{P}, \mathrm{N}$-ligand, $\mathrm{PdCl}_{2}$ exhibited a very good activity and stability also after seven runs without any precipitation of black palladium. In each run pure ethyl cinnamate was obtained in $>96 \%$ yield, whereas the ICP analysis indicated that leaching of $\mathrm{Pd}$ in the organic phase was below the detection limit $(<0.1 \mathrm{mg} / \mathrm{g})$. When the sole P-containing ligand was used lower yields were obtained although good stability was observed. At variance, in the N-containing ligand the palladium catalyst deactivated gradually during the recycle procedure with the obvious precipitation of Pd black, though its fresh activity was better than the corresponding hybrid P,N-ligand. Therefore, as suggested by the authors, the results seem to show that as a bidentate ligand, the P,N-functionalized IL, with a hemilabile ligation to metal center could offer the necessary insaturation site for the substrate (at $\mathrm{N}$-coordinating site) simultaneously holding the Pd by the P-ligand arm. Moreover, the bonding of the phosphine moiety to $\mathrm{C}-2$ position of the imidazolium, having an electron-withdrawing nature, results in a decreased electron density at the phosphorous center, leading to an improved oxidation tolerance of its self with consequent stability of the catalyst. This feature was evidenced also for the P-containing ligand in the above discussed ternary mixture.

Finally, although many of the works on Heck reaction are related to imidazolium based ILs, in 2006 an interesting paper highlighting the possibility to the use of a Brønsted guanidine acid-base ionic liquid as media and catalyst was published (Figure 14) [56].

Figure 14. Brønsted guanidine acid-base ionic liquid.

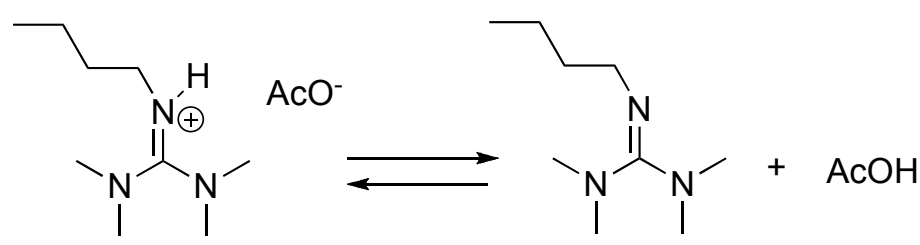

The basic butyltetramethylguanidinium acetate, prepared by neutralization of the corresponding guanidine with acetic acid, was used successful as solvent, ligand and base in the reactions of aryl halides with styrene and butyl acrylate at $140{ }^{\circ} \mathrm{C}$. High yields of the expected products were obtained in subsequent runs (the system was reused five times) until all acetate was converted to bromide. Determination of the palladium that remained in IL evidenced only a slight decrease. It is noteworthy that quantitative conversion was achieved within $0.25 \mathrm{~h}$ when $0.16 \mathrm{~mol} \%$ of $\mathrm{PdCl}_{2}$ was used; decreasing the catalyst loading to $0.01 \%$ still resulted in quantitative conversion although the reaction time was prolonged at $20 \mathrm{~h}$.

Considering that at elevated temperature the guanidinium based IL may dissociate into guanidine and acetic acid, the author suggested that the generated guanidine acts as a base and a ligand for active 
Pd species. The molecular structure of the corresponding $\mathrm{L}_{2} \mathrm{PdCl}_{2}$ complex was reported (Figure 15) and its activity as catalyst for the reaction between bromobenzene and styrene was tested in DMA.

Figure 15. The molecular structure of the Guanidine ${ }_{2} \mathrm{PdCl}_{2}$ complex.

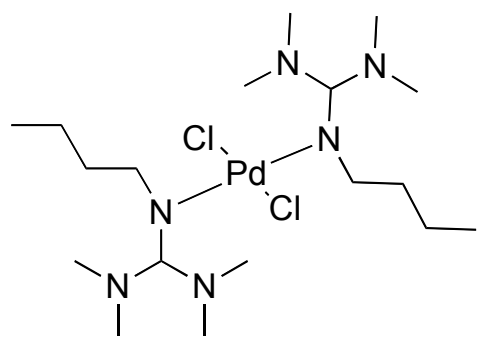

In conclusion, this simple IL is able to play multiple roles in this process: i) it acts as ligand stabilizing the activated $\operatorname{Pd}(0)$ during the reaction; ii) it offers a strong base to favor the $\beta$-hydride elimination; iii) it acts as a polar solvent increasing the reaction rate. Unfortunately, no other data or example of application of this kind of IL has been subsequently reported.

\section{Heterogeneous Heck Reaction in ILs}

To simplify processes and ensure reproducibility, process chemists generally gravitate toward reaction chemistry that can be run in a single common liquid phase. However, significant productivity advantages can frequently be achieved by employing multiple phases (i.e., liquid-liquid, gas-liquid, solid-liquid). As reported in the previous sections, liquid-liquid biphasic Heck processes involving ionic liquids and organic product phases have been the subject of intensive investigation since the ionic catalyst phase often induces excellent catalyst immobilization and also low miscibility with the organic products. However, application of these procedures in industrial processes is still hampered by the fact that these methodologies use large amounts of ILs. Moreover, in many cases liquid-liquid biphasic catalysis uses only fraction of the IL and of the dissolved catalyst. Finally, catalyst leaching cannot be completely avoided.

To increase catalyst performance and develop more sustainable and environmental benign reaction conditions, in the last decade several attempts have been done to perform the Heck reaction under heterogeneous conditions. The concept of confining a catalyst on porous supports is far from new, and several palladium catalyst reservoirs are commercially available; these systems have tested also in ILs. In 2001, the use of $\mathrm{Pd} / \mathrm{C}$ as a stable and inexpensive catalyst in $[\mathrm{bmim}]\left[\mathrm{PF}_{6}\right]$ in the presence of $\mathrm{Et}_{3} \mathrm{~N}$ was reported [57]; the procedure assured the re-cycle of the catalytic system without loss of activity. Moreover, ICP analysis of the ionic liquid performed before and after reaction revealed that the concentration of $\mathrm{Pd}$ in the ionic medium was negligible, suggesting that the $\mathrm{Pd} / \mathrm{C}$ catalyzed reaction occurs on the surface of $\mathrm{Pd}$ held on the carbon. More recently, the same research group has reported [58] the very facile and economically friendly immobilization of $\mathrm{Pd}(\mathrm{OAc})_{2}$ in silica gel pores, with the aid of $[\mathrm{bmim}]\left[\mathrm{PF}_{6}\right]$, and the application of this catalytic system in recyclable Heck reactions (figure 16). The catalyst immobilization on the silica gel was highly effective in dodecane at $150{ }^{\circ} \mathrm{C}$ giving a $95 \%$ average yield and a TON of 68,000 up to 6 th use. The use of a hydrocarbon solvent was however necessary to prevent removal of the IL layer from the silica. 
Figure 16. Immobilized $\mathrm{Pd}(\mathrm{OAc})_{2}$ in silica gel pores using [bmim] $\left[\mathrm{PF}_{6}\right]$.

Promising results in terms of both yield and sustainability, were obtained through the immobilization of $\mathrm{Pd}(\mathrm{OAc})_{2}$ on reversed phase amorphous silica gels, always with the aid of [bmim] $\mathrm{PF}_{6}$. In this case, a water compatible catalytic system was obtained [59]. The Heck reaction of iodobenzene with cyclohexyl acrylate using this catalyst, carried out in water at $100{ }^{\circ} \mathrm{C}$, was characterized up to the sixth re-use by an average 95\% yield with TON and TOF 1,600,000 and 71,000 $\left(\mathrm{h}^{-1}\right)$, respectively. Moreover, different by the reaction in dodecane, there is no need, for recycle use, to wash the recovered catalyst with alkaline solution to remove ammonium halide. It is noteworthy that when silica supported palladium complex catalysts were used for the reaction of iodobenzene with olefin also in $[\mathrm{bmim}]\left[\mathrm{PF}_{6}\right]$, although the system exhibited higher activity that in DMF, a dissolution of the catalyst from the silica support to the medium during the reaction was evidenced [60]. This latter process, therefore, although mediated by supported metal Pd may be considered to proceed as a quasihomogeneous process.

Support, solvent and form of palladium catalyst determine the intrinsic nature of the process and the possibility to have or not the direct involvement of Pd atoms located onto the support into the catalytic cycle. In this contest, a recent study of the Heck reaction between bromobenzene and styrene performed in tributylhexylammonium bistriflimide, using ultrafine particles of palladium metal supported onto hydrophilized mesoporous soot as the catalyst, has confirmed the fundamental role of the IL in the catalyst stabilization, also evidencing that the reaction occurs through a "true heterogeneous" mechanism [61].

Highly efficient and stable supported palladium nanoparticles have been obtained also by contacting a solution of $\mathrm{Pd}(\mathrm{OAc})_{2}$ with an ionic liquid- modified xerogel [62], containing a phosphinite functionalized IL (Figure 17) attached to the silica matrix able to act as both as complexing and reducing agent. 
Figure 17. Phosphinite functionalized IL.

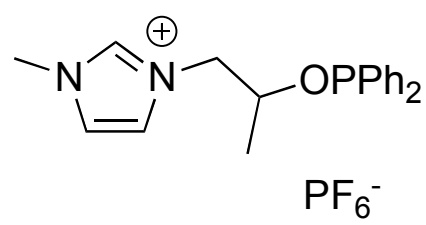

It is noteworthy that $\mathrm{Pd}(\mathrm{OAc})_{2}$ solution gives by interaction with this matrix highly dispersed uniformly sized Pd nanocatalysts, tightly supported on the surface of the silica and not embedded in the bulk of xerogel.

However, sol-gel processing has been also used to encapsulate $\mathrm{Pd}(\mathrm{OAc})_{2}$ catalyst into a ionic phase-confined silica gels [63]. Pd-doped ionogel pellets have been employed in the coupling reaction of ethyl acrylate with iodobenzene using toluene as solvent. No significant difference in the reaction rate, when compared to homogeneous system, was observed, whereas leaching tests showed that catalysts actually took place in the IL phase confined within the silica matrix.

But, silica and carbon are not the sole supports used. Palladium nanocolloids supported on chitosan have been found to be an efficient and recyclable catalyst for Heck arylation of alkenes using tetrabutylammonium bromide (TBAB) as solvent and tetrabutylammonium acetate (TBAA) as base [64]. The efficiency of this catalyst has been attributed to the stabilization of palladium colloids by the solvent and to a very fast $\mathrm{PdH}$ neutralization by the base. It is noteworthy that the conversion rate decreases significantly in imidazolium based IL (including [bmim]Br) whereas in TBAB recyclability is possible only using aryl iodides; when bromobenzene was used the efficiency of the catalyst decreased with a concomitant leaching of the palladium from the complex, attributed to a decomposition of $\mathrm{TBAB}$ at $130{ }^{\circ} \mathrm{C}$ (temperature necessary for reaction of bromobenzene) which destabilizes the nanocomposite.

Recently, also Pd nanoparticles immobilized on molecular sieves SBA-15 (thiol-modified mesoporous materials) using 1,1,3,3-tetramethylguanidinium lactate have been synthesized [65]. The Heck arylation of olefins using this catalytic system was carried out under solvent-free conditions; the model reaction, iodobenze- methyl acrylate proceeded smoothly and the yield of trans-methyl cinnamate was $93 \%$, even when the amount of Pd was $0.001 \mathrm{~mol} \%$. Moreover, no deactivation of the catalyst was observed after six repeated catalytic coupling reactions. It is noteworthy, that the reusability of the Pd catalyst supported on SBA-15 in the absence of the IL was significantly lower; it became an inactive white power after two recycles. The different behavior, with and without IL, has been attributed on the basis of transmission electronic microscope (TEM) images to the different size and distribution of the catalyst. In the presence of the IL, most of the Pd nanoparticles had before use a diameter in the range of 3-6 nm and they existed in the channels of the support. At variance, in the absence of the IL, the diameters of most Pd nanoparticles were in the range of 9-12 nm, bigger that the pore diameter of SBA-15, resulting in their existence on the outside surface of SBA-15. After, six recycles, most Pd nanoparticles on IL containing SBA-15 still exist in the channels, although some bigger Pd particles were formed, whereas in the absence of IL already after 2 recycles, most of the Pd disappeared and few Pd particles existed on the surface of the support. But, interesting results related to the catalytic mechanism of these systems have been obtained through filtration tests. The solid-free filtrate, obtained after separation of the catalyst before the end of the reaction, was able to continue to 
react, suggesting that the leaching of the active palladium species from the solid support occurred during the coupling. However, Pd re-deposited back onto the support after the end of the reaction.

Among the possible supports for Pd nanoparticles ionic polymers also have to be mentioned. A number of imidazolium-based polymers have been indeed synthesized (Figure 18), including poly(3(4-vinylbenzyl)-1-methylimidazolium chloride and bistriflimide [66], and their ability to stabilize metal nanoparticles has been tested in coupling processes, including the Heck reaction [67].

Figure 18. Imidazolium-based polymers.

In particular, it has been shown that highly stable Pd nanoparticles, protected by an imidazolium based ionic polymer in a functionalized IL, can be easily prepared by reduction with $\mathrm{NaBH}_{4}$. These viscous systems, containing Pd nanoparticles, are excellent pre-catalysts for Suzuki, Heck and Stille coupling reactions and can be stored without undergoing degradation for at least two years; compared to commercial $\mathrm{Pd} / \mathrm{C}$ systems that typically required $\mathrm{Pd}$ loading of $2-4 \mathrm{~mol} \%$ loading of $0.5-1.0 \mathrm{~mol} \%$ can be employed using these systems.

In all the above discussed systems the Pd catalyst is held in/on a more or less porous solid by physic absorption, sometimes using the ability of the IL to coordinate the active catalytic species. However, immobilization can also be obtained through the covalent anchoring of the catalysts to the support surface [68]. Trimethoxysilylpropyl functionalized ILs may been anchored to silica, via the reaction of the appended alkyl-silyl side branch tethered into the anion or cation. Using this approach to graft imidazolium cations onto pre-dried silica, the subsequent treatment with $\mathrm{PdCl}_{2}$, gave non-acidic supported palladium-based ILs to use in Suzuki-Miyaura coupling reactions [69]. But the same approach was used also to tether a N-heterocyclic carbene palladium/ionic liquid matrix on the silica surface (Scheme 17).

The latter system, constituted by grafted N-heterocyclic carbene palladium complexes in grafted ILs, was effectively applied to the Heck reaction of a wide variety of iodo and bromoarenes. The catalyst showed high thermal stability (up to $280{ }^{\circ} \mathrm{C}$ ) and could be recovered and reused for four cycles, giving a total TON $=36,600$. It is noteworthy that, TEM coupled with EDX analysis indicated the formation of Pd nanoparticles with irregular shape and wide-range size distribution confined inside the irregular pores of amorphous $\mathrm{SiO}_{2}$. 
Scheme 17. N-heterocyclic carbene palladium/IL matrix tethered on the silica surface.
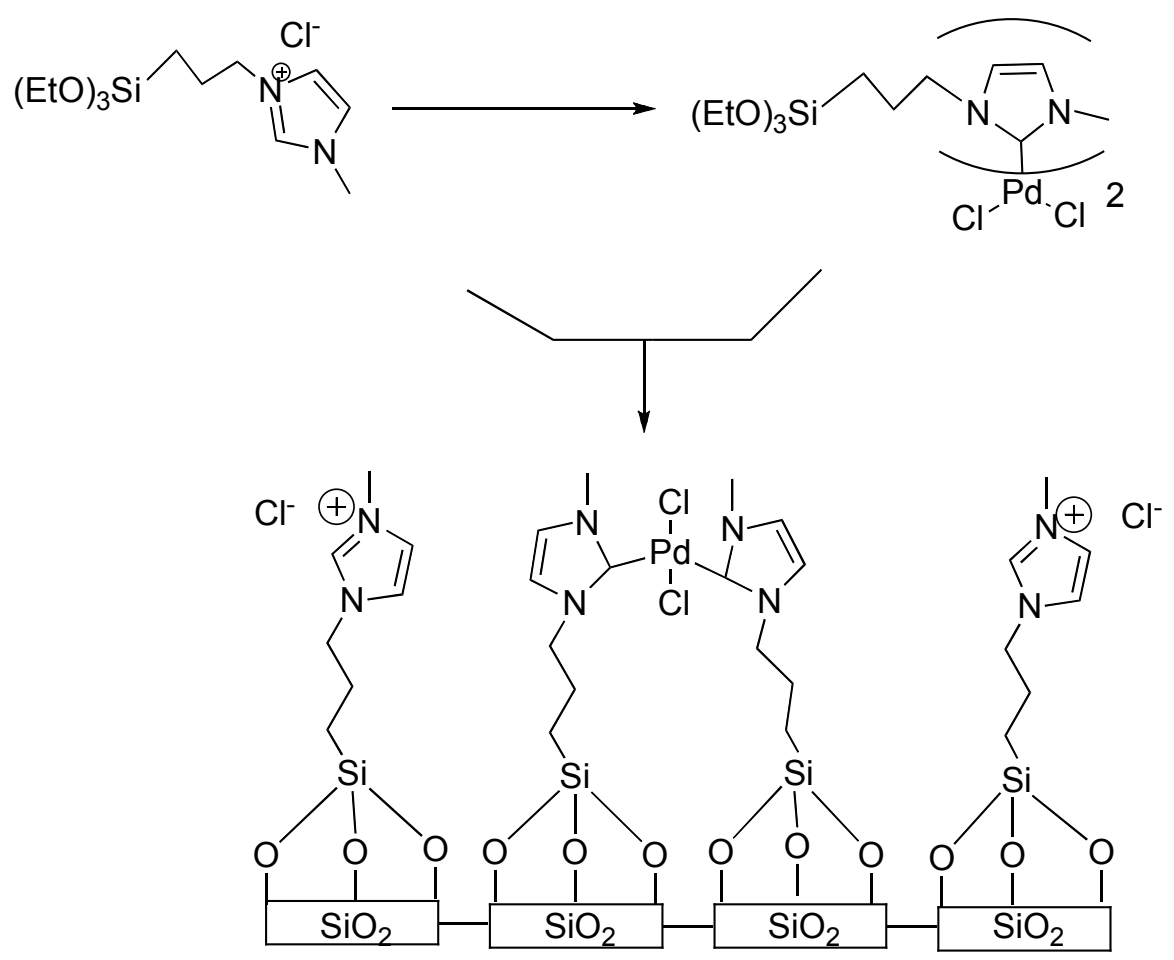

Finally, it is worth mention that polymeric beads of supported ILs (Figure 19), prepared via the covalent anchoring of an imidazolium salt to a PEG support, have also been used as a recyclable ( $100 \%$ yield after five cycles in the reaction of bromobenzene with styrene) catalytic system for the Heck reaction of aryl bromides and activated aryl chlorides [70]. Also in this case the drop in conversion starting from the sixth cycle was attributed to the accumulation of inorganic salts.

Figure 19. PEG supported ILs.

\section{The Role of ILs in the Heck Reaction: the "Ionic Liquid Effect"}

Ionic liquids constitute not only good solvents for the Heck reaction, due to their properties, but their unique ionic environment may change the course of the reaction, activating and/or stabilizing intermediates or transition states in the reaction mechanisms. As a consequence, performing the Heck reaction in these solvents may lead to an increasing in the reaction rate in comparison with "classical" solvents, to a stabilization of the catalytically active species and, in favorable cases, also to a control on the regio- and stereoselectivity of the coupling products. The nature of the ionic liquid however affects not only the kinetic constants of the single steps of this reaction but, probably, determines also the nature of the catalysts or pre-catalysts. The involvement of carbene complex, palladium nanoparticles and palladium anionic complexes seems to depend on the ionic liquid anion-cation structure. 


\subsection{ILs in ligand-free Heck reactions and their role in the stabilization of metal nanoparticles}

As reported above, the formation of palladium nanoparticles in the Heck reaction performed in ILs has been more times evidenced. Calò and co-workers described the use of Pd-NPs generated in situ by reaction of the carbene Pd precatalyst $\mathbf{A}$ in $\left[\mathrm{Bu}_{4} \mathrm{~N}\right] \mathrm{Br}$ using $\left[\mathrm{Bu}_{4} \mathrm{~N}\right][\mathrm{OAc}]$ as the base (Figure 20) $[26,28]$. They found that Pd-NPs are rapidly formed when $\left[\mathrm{Bu}_{4} \mathrm{~N}\right][\mathrm{OAc}]$ is added to $\mathbf{A}$ dissolved in $\left[\mathrm{Bu}_{4} \mathrm{~N}\right] \mathrm{Br}$ at $130{ }^{\circ} \mathrm{C}$. In addition to the formation of a black suspension, which is typical when NPs are involved, the authors isolated 2-oxo-3-methylbenzothiazole (B) arising from deligation of the carbene ligands in A (Figure 20).

Figure 20. Carbene palladium precatalyst (A) and 2-oxo-3-methylbenzothiazole (B).

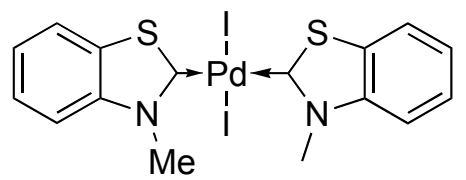

A<smiles>Cn1c(=O)sc2ccccc21</smiles>

B

Pd-NPs where confirmed by TEM analysis of a reaction sample [26]. Moreover, as already observed by Reetz and Westermann [71], Pd-NPs were also formed simply dissolving $\mathrm{Pd}(\mathrm{OAc})_{2}$ in $\left[\mathrm{Bu}_{4} \mathrm{~N}\right] \mathrm{Br}$ and adding $\left[\mathrm{Bu}_{4} \mathrm{~N}\right] \mathrm{OAc}$, obtaining rapidly a dark dispersion [26].

Pd-NPs dispersed in [BMIM] $\left[\mathrm{PF}_{6}\right]$ have been prepared also by Dupont and co-workers and tested in the coupling of aryl iodides with $n$-butylacrylate using $\mathrm{NEt}(i-\mathrm{Pr})_{2}$ as the base in a temperature range of $30-130{ }^{\circ} \mathrm{C}$ [72]. The Pd-NPs before and after the coupling were analyzed by TEM, and the palladium content of the organic phase during the arylation reaction was checked by ICP-AS. The results obtained in this study were interpreted as strong indications that Pd-NPs dispersed in the ionic liquid act as a reservoir of catalytically active Pd species, and that very probably the reaction proceeds through the oxidative addition of $\mathrm{PhI}$ on the NPs surface, and the oxidized Pd species thus formed are detached from the surface and enter in the main catalytic cycle [72]. However, more recently this definition has been considered not formally correct. In fact, when the $\operatorname{Pd}(0)$ agglomeration rate is quite high there is an increase in the contribution of a second catalytic cycle to substrate conversion, and this make impossible a definition of metallic palladium as a catalyst reservoir [19].

The non-linear dependence of reaction yield on catalyst concentration has also been associated with the formation of Pd-NPs as the reactive form of the catalyst. In fact, initially the $\operatorname{Pd}(0)$, formed by a rapid reduction in situ of the $\mathrm{Pd}(\mathrm{II})$ precatalyst, is in the form of Pd clusters that are stabilized to some extent by the ionic liquid (for example, it has been suggested that in ammonium halides an "electrosteric" stabilization of metal NPs is operative: the halide anions provide electrostatic stabilization, and the ammonium cations a steric stabilization [73]). If the oxidative addition reaction is slow, the clusters may undergo ripening to form large crystals that precipitate as Pd black. Hence, to prevent this it may be better to increase the substrate/catalyst ratio [74]. As an example, in a recently published protocol for the base-free Pd-catalyzed Heck reaction in $\left[\mathrm{Bu}_{4} \mathrm{~N}\right] \mathrm{Br}$, the yield of butylcinnamate formed by reaction of bromobenzene and butylacrylate strongly depends on the concentration of palladium. In particular, the maximum yield was obtained for $\mathrm{PdCl}_{2}\left(\mathrm{PhCN}_{2}\right.$ at 
$0.09 \mathrm{~mol} \%$, and for $\mathrm{PdCl}_{2}$ and $\mathrm{Pd}(\mathrm{OAc})_{2}$ at $c a .0 .4 \mathrm{~mol} \%$, while lower yields were obtained below and over that concentrations (Scheme 18) [75].

Scheme 18. Base-free Pd-catalyzed Heck reaction in $\left[\mathrm{Bu}_{4} \mathrm{~N}\right] \mathrm{Br}$.

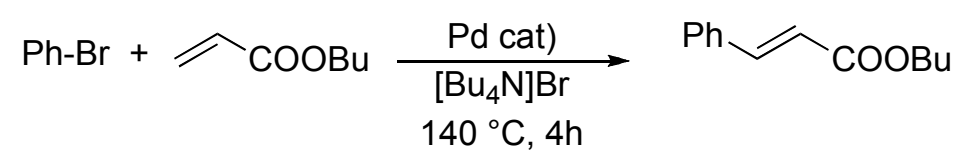

As stated, a similar behavior has been interpretated as the effect of Pd-NPs formation, but the authors suggested that also a concomitant formation of less active dimeric or polymeric $\operatorname{Pd}(\mathrm{II})$ complexes could also be considered another explanation of the observed concentration effect [75].

Palladium nanoparticles have been evidenced also in functionalized ILs [43]. TEM images evidence that nanoparticles isolated from $[\mathrm{bmim}]\left[\mathrm{BF}_{4}\right]$ and $\left[\mathrm{C}_{3} \mathrm{CNmim}\right]\left[\mathrm{BF}_{4}\right]$ have a similar diameter of ca. $5 \mathrm{~nm}$, but they show different morphologies. The nanoparticles obtained from nitrile functionalized ILs were well-separated, whereas those from $[\mathrm{bmim}]\left[\mathrm{BF}_{4}\right]$ formed nanoclusters up to ca. $30 \mathrm{~nm}$, suggesting that the nitrile group exerts a stabilizing effect and prevents aggregation. Nevertheless, in nitrile functionalized ILs the involvement of carbene complexes of the type, $\left[\left(\mathrm{C}_{3} \mathrm{CN}\right)_{2} \mathrm{im}\right]_{2}\left[\mathrm{PdCl}_{2}\right]$ as catalysts or precatalysts has been excluded: Heck reactions performed using the pre-formed $\left[\left(\mathrm{C}_{3} \mathrm{CN}\right)_{2} \mathrm{im}\right]_{2}\left[\mathrm{PdCl}_{2}\right]$ carbene complex were characterized by low conversions (ca. 2-8\%), when carried out under conditions giving $>95 \%$ yields with $\mathrm{PdCl}_{2}$. It is noteworthy that not only $\mathrm{PdCl}_{2}$ but also $\left[\left(\mathrm{C}_{3} \mathrm{Cdmim}\right]\left[\mathrm{PdCl}_{4}\right]\right.$ can act as an active pre-catalyst in the Heck reaction. $\left[\left(\mathrm{C}_{3} \mathrm{Cdmim}\right]\left[\mathrm{PdCl}_{4}\right]\right.$ is formed by addition of $\mathrm{PdCl}_{2}$ to $\left[\mathrm{C}_{3} \mathrm{CNmim}\right] \mathrm{Cl}$; also in nitrile functionalized ILs if the anion is a strong nucleophile, such as chloride, the preferential coordination of the chloride anion with the metal takes place. The resulting complex is however less catalytically active with respect $\mathrm{PdCl}_{2}$ or, more likely, less able to transform to the active species (Figure 21).

Figure 21. Palladium complexes with nitrile functionalized ILs.

\subsection{ILs as precursors of carbene ligands}

It is noteworthy that, despite the vast majority of the research in the area of ILs is focused on compounds derived from imidazole, due to the simplicity in preparing these derivatives and the generally lower melting points and viscosities as compared to other classes (such as ammonium-, phosphonium- or pyridinium-based ILs), at the beginning of the development of Heck protocols in ionic liquids they proved to be significantly less effective when compared to tetraalkylammonium salts in the absence of phosphine ligands [18,21]. However, it has been reported that the addition of a 
phosphine ligand when the reaction was carried out in $[\mathrm{BMIM}]\left[\mathrm{PF}_{6}\right]$ resulted in a dramatic increase in the reaction rate (Table 3) [18].

Table 3. Heck reaction in imidazole-based ILs.

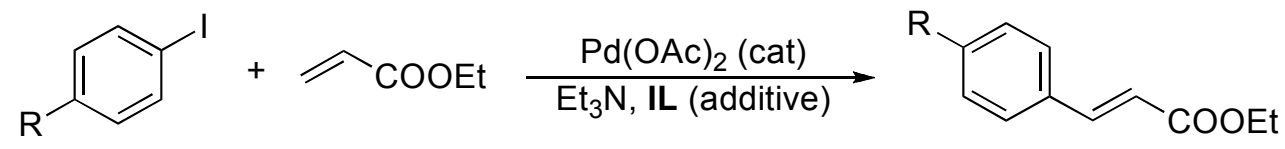

\begin{tabular}{cccccc}
\hline Entry & IL & Additive & Reaction temp. $\left({ }^{\circ} \mathbf{C}\right)$ & Reaction time (h) & Yield (\%) \\
\hline 1 & {$\left[\mathrm{C}_{6} \mathrm{Py}\right] \mathrm{Cl}$} & - & 40 & 24 & 99 \\
2 & {$[\mathrm{pmim}] \mathrm{Cl}$} & - & 80 & 72 & 10 \\
3 & {$[\mathrm{bmim}]\left[\mathrm{PF}_{6}\right]$} & - & 100 & 20 & 7 \\
4 & {$[\mathrm{bmim}]\left[\mathrm{PF}_{6}\right]$} & - & 140 & 18 & 94 \\
5 & {$[\mathrm{bmim}]\left[\mathrm{PF}_{6}\right]$} & $\mathrm{Ph}_{3} \mathrm{P}$ & 100 & 1 & $95-99$ \\
\hline
\end{tabular}

It is also interesting to note that, under phosphine-free conditions, the reaction was not effective at $100{ }^{\circ} \mathrm{C}$ (entry 3), but when the temperature was raised to $140{ }^{\circ} \mathrm{C}$ the required cinnamate was obtained in $94 \%$ yield (entry 4 ). This result was attributed, once again, to the formation of Pd-NPs, which became active as catalyst at $\mathrm{T}>100{ }^{\circ} \mathrm{C}[6]$.

Similarly, Herrmann and co-workers found that imidazole-based ILs gave less satisfactory results compared to tetraalkylammonium salts (Table 4) [21].

Table 4. Palladacycle-mediate Heck reaction in ILs.

$$
\begin{aligned}
& \mathrm{Ph}-\mathrm{Cl}+\underset{\mathrm{Ph}}{\stackrel{\text { Palladacycle }(0.5 \mathrm{~mol} \%)}{\mathrm{IL},\left[\mathrm{Ph}_{4} \mathrm{P}\right] \mathrm{Cl}(6 \mathrm{~mol} \%)}} \longrightarrow \mathrm{Ph} \backslash /{ }^{2} \mathrm{Ph} \\
& \text { (1.5 equiv) } \quad \mathrm{NaOAc}\left(1.2 \text { equiv), } 150^{\circ} \mathrm{C}\right.
\end{aligned}
$$

\begin{tabular}{cccc}
\hline Entry & IL & Reaction time (h) & GLC yield (\%) \\
\hline 1 & {$\left[\mathrm{Bu}_{4} \mathrm{~N}\right] \mathrm{Br}$} & 18 & 51 \\
2 & {$[\mathrm{pmim}] \mathrm{Br}$} & 19 & 22 \\
3 & {$[\mathrm{bpim}] \mathrm{Br}$} & 16 & 11 \\
4 & {$\left[\mathrm{bbim}_{\mathrm{PF}}\right.$} & 15 & 5 \\
\hline
\end{tabular}

It has to be noticed that a particularly low GLC yield was observed when the noncoordinating [ $\mathrm{PF}_{6}$ ] anion was used as counterion (entry 4). All these results clearly suggested that either different catalytically active species are involved in relation with the used ionic liquids, or that the reaction proceeds through different mechanistic pathways.

It is well established that the $\alpha$-position of imidazolium salts can be deprotonated to form stabilized carbenes [76], and that these Arduengo-type carbene are employed as ligands in the area of transition metal-catalyzed reactions [77]. In 2000, as already stated, Xiao and co-workers obtained the first convincing evidence that carbene species are involved in Heck reactions carried out in imidazoliumbased ionic liquids (Scheme 19) [29]. 
Scheme 19. Heck reaction in imidazolium based ILs.

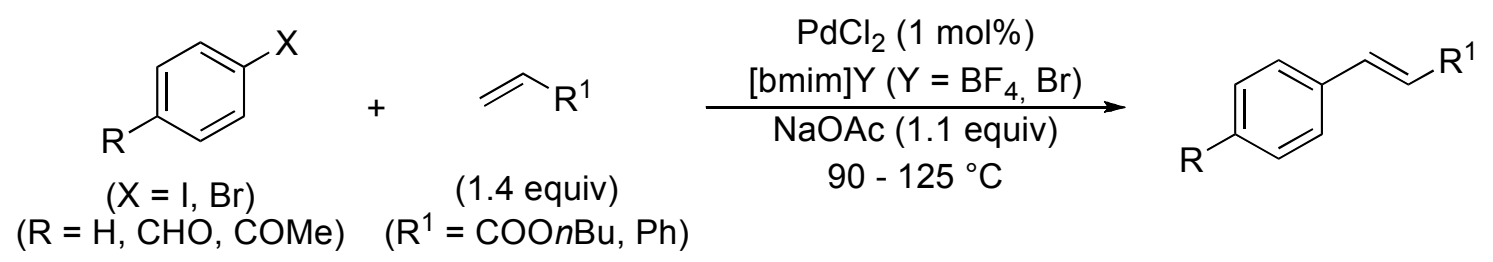

They found that the Heck reaction proceeded markedly more efficiently in the ionic liquid containing bromide as the counterion than in the analogous tetrafluoroborate salt. In conjunction with these observations, carbene complexes have been isolated by reaction of [bmim]Br with $\mathrm{Pd}(\mathrm{OAc})_{2}$, but non-carbene species were detected when $[\mathrm{bmim}]\left[\mathrm{BF}_{4}\right]$ was used. The authors attributed the stability of the isolated carbene complex $\mathbf{C}$ (Figure 22) to the bromide ions $\left(\mathrm{X}=\mathrm{Br}\right.$ ), while the presence of $\left[\mathrm{BF}_{4}\right]^{-}$ probably converts $\mathbf{C}$ into an inactive complex [29].

Figure 22. Isolated carbene palladium complex.

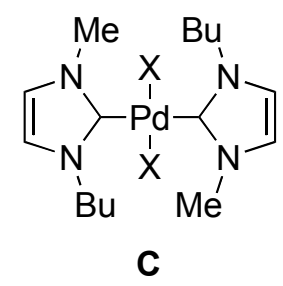

Subsequent studies proved that the acidity of the $\alpha$-position in imidazolium salts depends not only on the structure of the heterocyclic moiety, but also on the nature of the anionic partner [50,79]. These studies revealed that more basic anions (such as halides) resulted in imidazolium salts that undergo an easy deprotonation even in the absence of any added base (thus generating carbenes), while weakly coordinating anions (such as tetrafluoroborate or hexafluorophosphate anions) resulted in salts which necessitate strong external bases for the C-2 deprotonation [79]. As a consequence, it may be possible to conclude that imidazolium halides, or imidazolium-based ionic liquids containing coordinating (basic) anions, give rise to carbene Pd complexes which resulted stabilized by the same anions, while imidazolium salts containing non-coordinating anions furnished inactive Pd species, which can convert to Pd-NPs at elevated temperatures [73] or into active Pd catalysts in the presence of phosphine ligands [18].

These conclusions are in agreement with the negative result observed when a 2-methyl substituted glycerol-containing imidazolium salt, which cannot generate carbenes in the reaction medium, was used as the solvent in the Heck arylation of ethyl acrylate. In contrast, the analogous $\mathrm{Cl}$ or $\mathrm{Br}$ salts, that may be converted into Arduengo-type carbene ligands, resulted good solvents for the Heck reaction promoted by $\mathrm{PdCl}_{2}$ in the presence of $\mathrm{NaOAc}$ as the base [49].

Moreover, Lauth-de Viguerie and co-workers reported the use of palladate salts, generated from $\mathrm{PdCl}_{2}$ and [BMIM]Cl, as catalysts for the Heck reaction in [BMIM] $\left[\mathrm{PF}_{6}\right]$, which proved to be more effective than traditional precatalysts [80]. These results were attributed to the presence of NPs which served as reservoir of $\mathrm{Pd}$ species, while the formation of carbenes was excluded. 


\subsection{ILs and regioselectivity in the Heck reaction}

The regioselectivity of the Heck reaction is considered to be affected by the two generally accepted pathways: ionic versus neutral, as illustrated in Scheme 20 [81].

Scheme 20. Proposed neutral and ionic pathways for the Heck reaction.

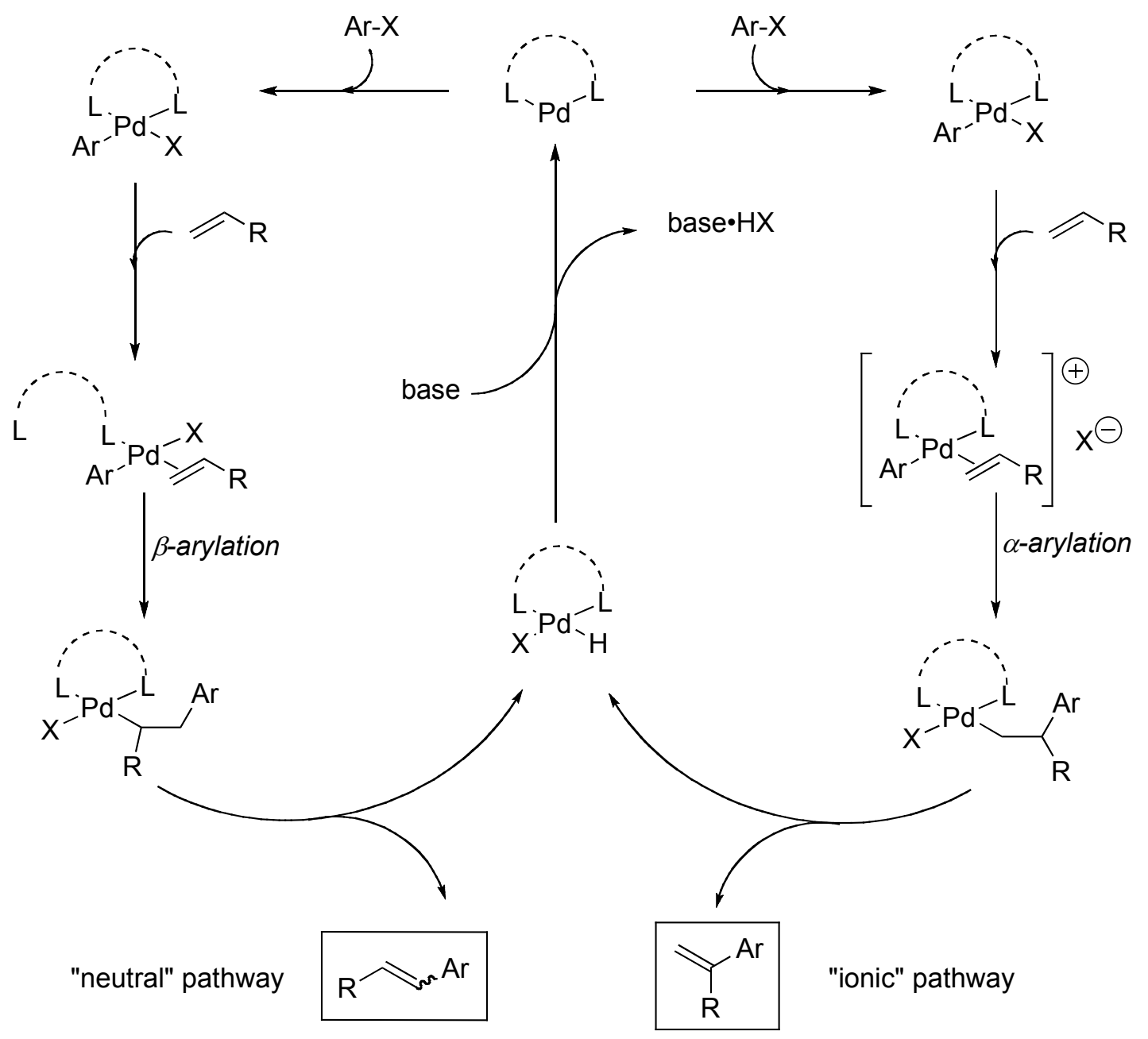

As depicted in Scheme 20, the neutral pathway, which is more sensitive to steric factors than to electronic factors, leads mainly to the formation of linear or $\beta$-substituted alkenes, while the ionic pathway, which depends on electronic factors than on steric factors, prevalently yields branched or $\alpha$ products. The neutral pathway is characterized by dissociation of one of the coordinating neutral ligand L, while ionic pathway generates a vacant coordination site through the dissociation of the (pseudo)halide anion. As a consequence, with monodentate ligands and aryl halides the neutral pathway should dominate due to the easy dissociation of the ligand in comparison with the relatively strong Pd-X bond. In contrast, the liability of Pd-Y bond (where Y= OTf, OMs, OTs) means that the ionic route should be preferred when using low-coordinating anions, particularly in the presence of chelating bidentate ligands [31,83].

For reactions involving electron-deficient olefins $(\mathrm{R}=\mathrm{EWG})$ under "normal" Heck conditions, that imply the use of monodentate phosphines and aryl/vinyl halides, the products usually result from arylation/vinylation at the terminal $\beta$-position through the neutral pathway. However, under similar 
conditions the observed regioselectivity when electron-rich olefins $(\mathrm{R}=\mathrm{EDG})$ are reacted with halides might be poor, and a mixture of products is often obtained [11,83]. In contrast, the promotion of the ionic pathway by using bidentate ligands and pseudohalides such as triflates, tosylates or mesylates as labile counterions, as showed by Hallberg [11] and by Cabri [83], generated a highly reactive cationic palladium complex and resulted in an efficient regioselective $\alpha$-arylation/vinylation of electron-rich olefins.

Unfortunately, problems such as poor availability, high cost and thermal liability limited the synthetic use of this approach, and now aryl/vinyl halides are used in the presence of a halide scavenger such as silver or thallium salts. However, the cost of silver and the toxicity of thallium severely prevent their use on a large scale.

To overcome these problems, Xiao and co-workers reported the use of imidazolium-based ionic liquids in conjunction with Pd-dppp precatalyst for highly regioselective Heck arylations of electronrich olefins $[31,84,85]$. As previously discussed, they supposed that the ionic pathway might be promoted by using ionic liquids as solvents, producing branched olefins without halide scavengers, according to the recent kinetic studies made by Amatore, Jutand and co-workers [86,87]. The strong electrostatic interactions existing in an ionic liquid would favour the generation of a Pd-olefin cation and a halide anion from two neutral precursors over the formation of a neutral Pd-olefin intermediate. In fact, they were able to obtain regioselectively and with high chemical yields $\alpha$-arylated olefins starting from electron-rich olefins such as vinyl ethers, enamides, allyltrimethylsilane (Scheme 21) [31,84].

Scheme 21. $\alpha$-Arylated olefins from electron-rich olefins.

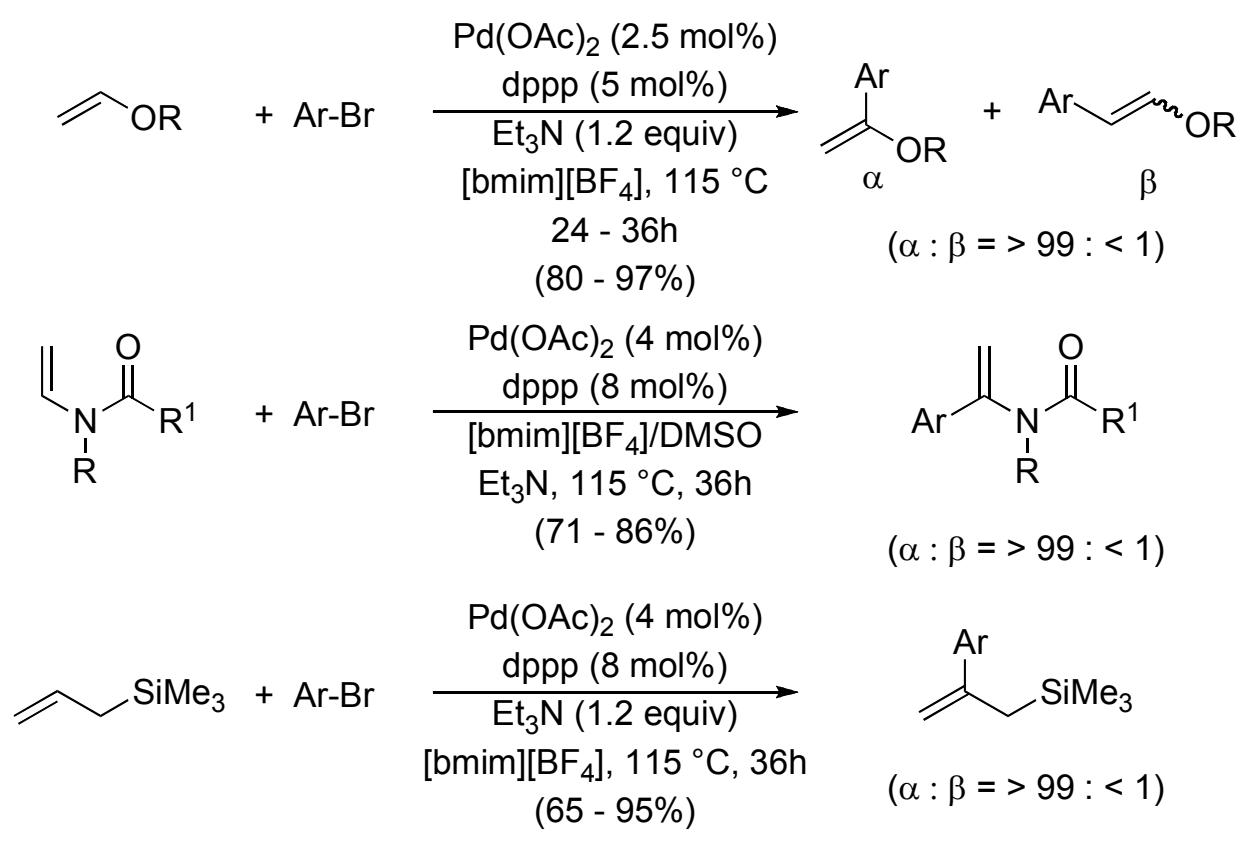

In addition, the group of Xiao observed that hydrogen-donating salts such as $\left[\mathrm{HNEt}_{3}\right]\left[\mathrm{BF}_{4}\right]$ could increase both the rate and the selectivity in ionic as well in molecular solvents, presumably by facilitating dissociation of bromide from Pd(II) complex (see eq.1) [85]. 
The selectivity of the Heck reaction is influenced not only by the reaction pathway, ionic or neutral, but also by other parameters including, among others, the choice of additives and the structure of the coupling partners.

The influence of the base and the chosen ionic liquid on the selectivity was evidenced by Calò and co-workers [88]. In particular, they found that using $\left[\mathrm{Bu}_{4} \mathrm{~N}\right][\mathrm{OAc}]$ dually as solvent and base, the Heck arylation of allylic alcohols under phosphine-free conditions resulted highly selective towards the formation of aromatic conjugated alcohols, while with $\left[\mathrm{Bu}_{4} \mathrm{~N}\right] \mathrm{Br}$ as solvent and $\mathrm{NaHCO}_{3}$ as the base the aromatic carbonyl compounds were selectively obtained (Scheme 22) [88].

Scheme 22. Heck arylation of allylic alcohols.

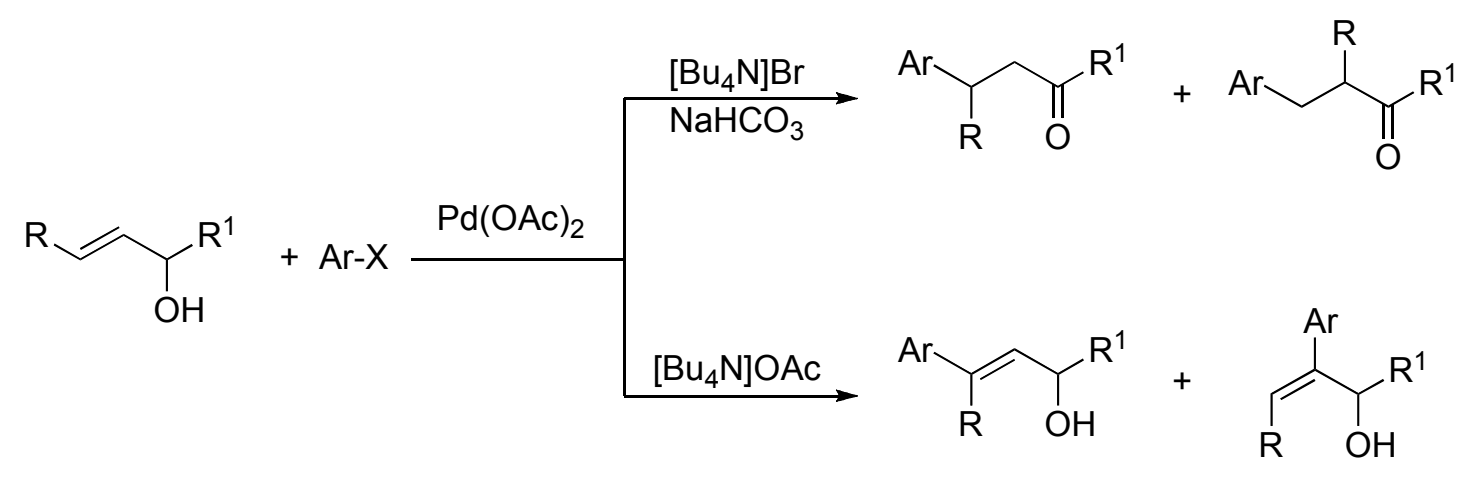

The authors, in order to explain the obtained results, supposed that the reaction can follow two different pathways, depending on the nature of the ligand $(\mathrm{X})$ bonded to palladium before the migratory insertion of the aryl group on the olefinic double bond (Scheme 23) [88].

Scheme 23. Possible reaction pathways.

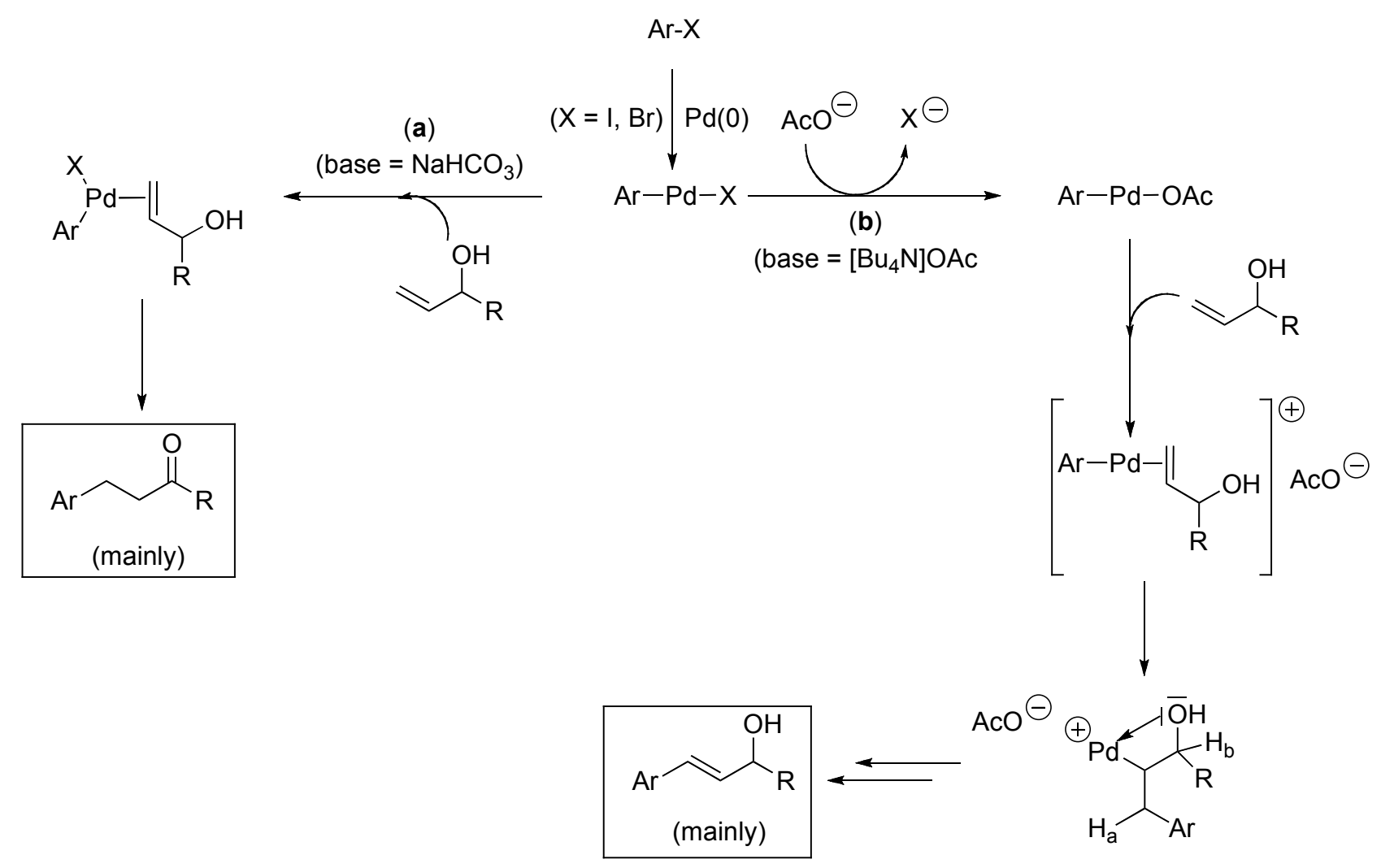


In particular, when $\left[\mathrm{Bu}_{4} \mathrm{~N}\right] \mathrm{Br}$ is used as solvent, and a conventional base such as $\mathrm{NaHCO}_{3}$ is employed, ligand $\mathrm{X}$ will be bromide or iodide anion (path a) and the reaction follows the neutral pathway (path a). For steric reasons, the migratory insertion of the aryl group predominantly occurs to the $\beta$-position of the alkenol, giving rise to $\beta$-arylated carbonyl products.

In contrast, when $\left[\mathrm{Bu}_{4} \mathrm{~N}\right][\mathrm{OAc}]$ is used as the reaction medium, an anionic metathesis probably occurs, and the acetate anion readily dissociates to give a cationic complex. This may explain the higher catalytic activity displayed by $\mathrm{Pd}(\mathrm{OAc})_{2}$ in $\left[\mathrm{Bu}_{4} \mathrm{~N}\right][\mathrm{OAc}]$, which allows the metal to activate iodo- and bromoarenes at low reaction temperatures (r.t. and $60{ }^{\circ} \mathrm{C}$, respectively, in contrast with the $100{ }^{\circ} \mathrm{C}$ and $130{ }^{\circ} \mathrm{C}$ required in $\left[\mathrm{Bu}_{4} \mathrm{~N}\right] \mathrm{Br}$ ). In this case, the migratory insertion on the double bond occurs prevalently on the $\beta$-position due to the formation of a chelate structure, which impedes also the hydrogen atom $\left(\mathrm{H}_{\mathrm{B}}\right)$ to adopt the syn-relationship with $\mathrm{Pd}$, necessary for the $\beta$-elimination. Hence, the abstraction of the benzylic hydrogen atom $\left(\mathrm{H}_{\mathrm{A}}\right)$ remains the only possible pathway.

\section{Conclusions}

The research of more sustainable procedures prompted organic chemists to look for more ecocompatible and more economical transition metal-catalyzed reactions. In the last ten years, a growing number of palladium catalyzed Heck reactions in ILs have been proposed as greener alternative to the classical cross-coupling procedure. Homogeneous and heterogeneous conditions have been explored showing that ILs are not only suitable solvents for the Heck reaction, but their unique physicochemical properties are able to change the course of the reaction, activating and/or stabilizing intermediates or transition states in the reaction mechanisms. Consequently, Heck reactions performed in ILs, or ILs containing environments, may have higher reaction rates, and may be characterized by a higher control on the regio- and stereoselectivity of the coupling products. The involvement of carbene complex, palladium nanoparticles and palladium anionic complexes has been evidenced depending on ILs structure and reaction conditions. In spite of the numerous interesting reports mentioned in this review, the study of the Heck reaction in ILs is still strongly related to the development of the IL; only simple reactions such as the coupling of aryl halides with cinnamates or styrene have been investigated. Thus, in the future, the use of ILs in Heck reactions involving more complicated substrates could give important indications about the possibility of application of these alternative media on large scale reactions.

\section{References}

1. Rogers, R.D., Seddon, K.R., Eds. Ionic Liquids IIIB: Fundamentals, Progress, Challenges, and Opportunities-Transformations and Processes. ACS Symp. Ser.; American Chemical Society: Washington, D.C., USA, 2005; Volume 902.

2. Rogers, R.D., Seddon, K.R., Eds. Ionic Liquids IIIA: Fundamentals, Progress, Challenges, and Opportunities-Properties and Structure; ACS Symp. Ser.; American Chemical Society: Washington D.C., USA, 2005; Volume 901.

3. Wasserscheid, P.; Welton, T., Eds. Ionic Liquids in Synthesis, 2nd ed.; Wiley-VCH: Weinheim, Germany, 2007. 
4. Scammells, J.; Scott, J.L.; Singer, R.D. Ionic Liquids: the Neglected Issues. Aust. J. Chem. 2005, 58, 155-169.

5. Anderson, J.L.; Armstrong, D.W.; Wei, G.-T. Ionic Liquids in Analytical Chemistry. Anal. Chem. 2006, 78, 2892-2902.

6. Earle, J.; Seddon, K.R. Ionic Liquids. Green Solvents for the Future. Pure Appl. Chem. 2000, 72, 1391-1398.

7. Welton, T. Room-Temperature Ionic Liquids. Solvents for Synthesis and Catalysis. Chem. Rev. 1999, 99, 2071-2084.

8. Endres, F.; El Abedin, S.Z. Air and water stable ionic liquids in physical chemistry. Phys. Chem. Chem. Phys. 2006, 8, 2101-2116.

9. van Rantwijk, F.; Lau, R.M.; Sheldon, R.A. Biocatalysis in Ionic Liquids. Trends Biotechnol. 2003, 21, 131-138.

10. Beletskaya, I.P.; Cheprakov, A.V. The Heck reaction as a sharpening stone of palladium catalysis. Chem. Rev. 2000, 100, 3009-3066.

11. Daves, G.D., Jr.; Hallberg, A. 1,2-Additions to heteroatom-substituted olefins by organopalladium reagents. Chem. Rev. 1989, 89, 1433-1445.

12. Trzeciak, A.M.; Ziòlkowski, J.J. The role of ionic liquids in palladium-catalyzed C-C bondforming reactions. In Advances Organometallic Chemistry Research; Yamamoto, K., Ed.; Nova Science Publishers: NewYork, NY, USA, 2007; p. 177.

13. Liu, Y.; Wang, S.-S.; Liu, W.; Wan, Q.-X.; Wu, H.-H.; Gao, G.-H. Transition-metal catalyzed carbon-carbon couplings mediated with functionalized ionic liquids, supported-ionic liquid phase, or ionic liquid media. Curr. Org. Chem. 2009, 13, 1322-1346.

14. Oestreich, M. The Mizoroki-Heck Reaction; John Wiley \& Sons: New York, USA, 2009.

15. Jeffery, T. Palladium-catalysed vinylation of organic halides under solid-liquid phase transfer conditions. J. Chem. Soc. Chem. Commun. 1984, 1287-1289.

16. Kaufmann, D.; Nouroozian, M.; Henze, H. Molten salts as an efficient medium for palladium catalyzed C-C coupling reactions. Synlett 1996, 1091-1092.

17. Slagt, V.F.; de Vries, A.H.M.; de Vries, J.G.; Kellogg R.M. Practical aspects of carbontcarbon cross-coupling reactions using heteroarenes. Org. Proc. Res. Devel. 2010, 14, 30-47.

18. Carmichael, A.J.; Earle, M.J.; Holbrey, J.D.; Mc Cormac, P.B.; Seddon, K.R. The Heck reaction in ionic liquids: A multiphasic catalyst system. Org. Lett. 1999, 1, 997-1000.

19. Schmidt, A.F.; Al Haleipa, A.; Smirnov, V.V. Interplays between reactions within and without the catalytic cycle of the Heck reaction as a clue to the optimization of the synthetic protocol. Synlett 2006, 2861-2878, and references cited therein.

20. Jeffery, T. On the efficiency of tetraalkylammonium salts in Heck type reactions. Tetrahedron 1996, 52, 10113-10130.

21. Herrmann, W.A.; Böhm, V.P.W. Heck reaction catalyzed by phospha-palladacycles in nonaqueous ionic liquids. J. Organomet. Chem. 1999, 572, 141-145.

22. Böhm, V.P.W.; Herrmann, W.A. Coordination chemistry and mechanisms of metal-catalyzed C-C coupling reactions, Part 12 Nonaqueous Ionic Liquids: Superior Reaction Media for the Catalytic Heck-Vinylation of Chloroarenes. Chem Eur. J. 2000, 6, 1017-1025. 
23. Battistuzzi, G.; Cacchi, S.; Fabrizi, G. A molten $n-\mathrm{Bu}_{4} \mathrm{NOAc} / n-\mathrm{Bu}_{4} \mathrm{NBr}$ mixture as an efficient medium for the stereoselective synthesis of $(E)$ - and (Z)-3,3-diarylacrylates. Synlett 2002, 439-442.

24. Bouquillon, S.; Gauchegui, B.; Estrine, B.; Hénin, F.; Muzart, J. Heck arylation of allylic alcohols in molten salts. J. Organomet. Chem. 2001, 634, 153-156.

25. Calò, V.; Nacci, A.; Monopoli, A. Effects of ionic liquids on Pd-catalysed carbon-carbon bond formation. Eur. J. Org. Chem. 2006, 3791-3802.

26. Calò, V.; Nacci, A.; Monopoli, A.; Laera, S.; Cioffi, N. Pd nanoparticles catalyzed stereospecific synthesis of $\beta$-aryl cinnamic esters in ionic liquids. J. Org. Chem. 2003, 68, 2929-2933.

27. Calò, V.; Nacci, A.; Monopoli, A.; Detomaso, A.; Iliade, P. Pd nanoparticle catalyzed Heck arylation of 1,2-disubstituted alkenes in ionic liquids. Study on factors affecting the regioselectivity of the coupling process. Organometallics 2003, 22, 4193-4197.

28. Calò, V.; Nacci, A.; Monopoli, A.; Cotugno, P. Heck ractions with palladium nanoparticles in ionic liquids: coupling of aryl chlorides with deactivated olefins. Angew. Chem. Int. Ed. 2009, 48, 6101-6103.

29. Xu, L.; Chen, W.; Xiao, J. Heck reaction in ionic liquids and the in situ identification of Nheterocyclic carbene complexes of palladium. Organometallics 2000, 19, 1123-1127.

30. Wu, X.; Mo, J.; Li, X.; Hyder, Z.; Xiao, J. Green chemistry: C-C coupling and asymmetric reduction by innovative catalysis. Prog. Nat. Sci. 2008, 18, 639-652.

31. Mo, J.; Xu, L.; Xiao, J. Ionic liquid promoted, highly regioselective Heck arylation of electronrich olefins by aryl halides. J. Am. Chem. Soc. 2005, 127, 751-760.

32. Mo, J.; Xiao, J. The Heck reaction of electron-rich olefins with regiocontrol by hydrogen-bond donors. Angew. Chem. Int. Ed. 2006, 45, 4152-4157.

33. Xie, X.; Chen, B.; Lu, J.; Han, J.; She, X.; Pan, X. Synthesis of benzofurans in ionic liquid by a $\mathrm{PdCl}_{2}$-catalyzed intramolecular Heck reaction. Tetrahedron Lett. 2004, 45, 6235-6237.

34. Kabalka, G.W.; Dong, G.; Venkatain, B. Investigation of the behavior of arenediazonium salts with olefins in $\mathrm{BmimPF}_{6}$.Tetrahedron Lett. 2004, 45, 2775-2777.

35. Xiao, J.C; Twamley, B.; Shreeve, J.M. An ionic liquid-coordinated palladium complex: a highly efficient and recyclable catalyst for the Heck reaction. Org. Lett. 2004, 6, 3845-3847.

36. Wang, R.; Piekarski, M.P.; Shreeve, J. New types of pyrazolyl-functionalized 2methylimidazolium-based ionic liquids and their palladium(II) complexes: highly efficient, recyclable catalysts for C-C coupling reactions. Org. Biomol. Chem. 2006, 4, 1878-1886.

37. Wang, R.; Zeng, Z.; Twamley, B.; Piekarski, M.M.; Shreeve, J. Synthesis and characterization of pyrazolyl-functionalized imidazolium-based ionic liquids and hemilabile palladium(II) carbene complex catalyzed Heck reaction. Eur. J. Org. Chem. 2007, 655-661.

38. Wang, R.; Twamley, B.; Shreeve, J. A highly efficient, recyclable catalyst for $\mathrm{C}-\mathrm{C}$ coupling reactions in ionic liquids: pyrazolyl-functionalized N-heterocyclic carbene complex of palladium(II). J. Org. Chem. 2006, 71, 426-429.

39. Vergas, V.C.; Rubio, R.J.; Holis, T.K.; Salcido, M.E. Efficient route to 1,3-Di-Nimidazolylbenzene. A comparison of monodentate vs bidentate carbenes in Pd-catalyzed cross coupling. Org. Lett. 2003, 5, 4847-4849. 
40. Jin, C.M.; Twamley, B.; Shreeve, J. Low-melting dialkyl- and bis(polyfluoroalkyl)-substituted 1,1'-methylene-bis(imidazolium) and 1,1'-methylenebis(1,2,4-triazolium) bis(trifluoromethanesulfonyl) amides: ionic liquids leading to bis(N-heterocyclic carbene) complexes of palladium. Organometallics 2005, 24, 3020-3023.

41. Wang, R.; Jin, C.M.; Twamley, B.; Shreeve, J. Syntheses and characterization of unsymmetric dicationic salts incorporating imidazolium and triazolium functionalities. Inorg. Chem. 2006, 45, 6396-6403.

42. Iranpoor, N.; Firouzabadi, H.; Azadi, R. An imidazolium-based phosphinite ionic liquid (IL$\mathrm{OPPh}_{2}$ ) as a reusable reaction medium and $\mathrm{Pd}^{\mathrm{II}}$ ligand in Heck reactions of aryl halides with styrene and $n$-butyl acrylate. Eur. J. Org. Chem. 2007, 2197-2201.

43. Zhao, D.; Fei,. Z.; Geldbach, T.J.; Scopelliti, R.; Dyson, P.J. Nitrile-functionalized pyridinium ionic liquids: synthesis, characterization, and their application in carbon-carbon coupling reactions. J. Am. Chem. Soc. 2004, 126, 15876-15882.

44. Chiappe, C.; Pieraccini, D.; Zhao, D.; Fei, Z.; Dyson, P.J. Remarkable anion and cation effects on Stille reactions in functionalised ionic liquids. Adv. Synth. Catal. 2006, 348, 68-74.

45. Fei, Z.; Zhao, D.; Pieraccini, D.; Ang, W.H.; Geldbach, T.J.; Scopelliti, R.; Chiappe, C.; Dyson, P.J. Development of nitrile-functionalized ionic liquids for $\mathrm{C}-\mathrm{C}$ coupling reactions: implication of carbene and nanoparticle catalysts. Organometallics 2007, 26, 1588-1598.

46. Ye, C.; Xiao, J.C.; Twamley, B.; LaLonde, A.D.; Norton, M.G.; Shreeve, J.M. Basic ionic liquids: facile access for Carbon-Carbon bond formation reactions and ready access to palladium nanoparticles. Eur. J. Org. Chem. 2007, 5095-5011.

47. Chiappe, C.; Melai, B.; Sanzone, A.; Valentini, G. Basic ionic liquids based on monoquaternized 1,4-diazobicyclo2.2.2octane (dabco) and dicyanamide anion: Physicochemical and solvent properties. Pure Appl. Chem. 2009, 81, 2035-2043.

48. Handy, S.T.; Okello, M.; Dickenson, G. Solvents from biorenewable sources: ionic liquids based on fructose. Org. Lett. 2003, 5, 2513-2515.

49. Bellina, F.; Bertoli, A.; Melai, B.; Scalesse, F.; Signori, F.; Chiappe, C. Synthesis and properties of glycerylimidazolium based ionic liquids: A promising class of task-specific ionic liquids. Green Chem. 2009, 11, 622-629.

50. Sheldon, R. Catalytic reactions in ionic liquids. Chem. Comm. 2001, 2399-2407.

51. Cai, Y.; Liu, Y. Efficient palladium-catalyzed Heck reactions mediated by diol-functionalized imidzolium ionic liquids. Cat. Comm. 2009, 10, 1390-1393.

52. Cai, Y.; Lu, Y.; Liu, Y.; Gao, G.H. Imidazolium ionic liquid-supported diol: an efficient and recyclable phosphine-free ligand for palladium catalyzed Heck reaction. Catal. Lett.2007, 119, 154-158.

53. Wang, L.; Li, H.; Li, P. Task-specific ionic liquid as base, ligand and reaction medium for the palladium-catalyzed Heck reaction. Tetrahedron 2008, 65, 364-368.

54. Wan, Q.X.; Liu, Y.; Lu, Y.; Li, M.; Wu, H.H. Palladium-catalyzed Heck reaction in the multifunctionalized ionic liquid compositions. Catal. Lett.2008, 121, 331-336.

55. Wan, Q.X.; Liu, Y.; Cai, Y.Q. A hybrid P,N-ligand functionalized imidazolium salt for palladium- catalyzed Heck reactions in ionic liquid solution. Catal. Lett. 2009, 127, 386-391. 
56. Li, S.; Li, Y.; Xie, H.; Zhang, S.; Xu, J. Bronsted guanidine acid-base ionic liquids: novel reaction media for the palladium catalyzed Heck reaction. Org. Lett. 2006, 8, 391-394.

57. Hagiwara, H.; Shimizu, Y.; Hoshi, T.; Suzuki, T.; Ando, M.; Ohkubo, K.; Yokoyama, C. Heterogeneous Heck reaction catalyzed by $\mathrm{Pd} / \mathrm{C}$ in ionic liquid. Tetrahedron Lett. 2001, 42, 4349-4351.

58. Hagiwara, H.; Sugawara, Y.; Isobe, K.; Hoshi, T.; Suzuki, T. Immobilization of Pd(OAc) 2 in ionic liquid on silica: application to sustainable Mizoroki-Heck reaction. Org. Lett. 2004, 6, 23252328.

59. Hagiwara, H.; Sugawara, Y.; Hoshi, T.; Suzuki, T. Sustainable Mizoroki-Heck reaction in water: remarkably high activity of $\mathrm{Pd}(\mathrm{OAc})_{2}$ immobilized on reversed phase silica gel with the aid of an ionic liquid. Chem. Comm. 2005, 2942-2944.

60. Okubo, K.; Shirai, M.; Yokoyama, C. Heck reactions in non-aqueous ionic liquid using silica supported palladium complex catalysts. Tetrahedron Lett. 2002, 43, 7115-7118.

61. Aslanov, L.A.; Kabachii, Y.A.; Kochev, S.Yu.; Romanovsky, B.V.; Valetsky, P.M.; Volkov, V.V.; Yatsenko, A.V.; Zakharov, V.N. Mesoporous soot-supported palladium as a heterogeneous catalyst for the Heck reaction in ionic liquids. Mendeleev Commun. 2008, 18, 334-335.

62. Safavi, A.; Maleki, N.; Iranpoor, N.; Firouzabadi, H.; Banazadeh, A.R.; Azadi, R.; Sedaghati, F. Highly efficient and stable palladium nanocatalysts on an ionic liquid-modified xerogel. Chem. Commun. 2008, 6155-6157.

63. Volland, S.; Gruit, M.; Régnier, T.; Viau, L.; Lavastre, O.; Vioux, A. Encapsulation of Pd(OAc) $)_{2}$ catalyst in an ionic liquid phase confined in silica gels. Application to Heck-Mizoroki reaction. New J. Chem. 2009, 33, 2015-2021.

64. Calò, V.; Nacci, A.; Monopoli, A.; Fornaro, A.; Sabbatini, L.; Cioffi, N.; Ditaranto, N. Heck reaction catalyzed by nanosized palladium on chitosan in ionic liquid. Organometallics 2004, 23, 5154-5158.

65. Ma, X.; Zhou, Y.; Zhang, J.; Zhu, A.; Jiang, T.; Han, B. Solvent-free Heck reaction catalyzed by a recyclable Pd catalyst supported on SBA-15 via an ionic liquid. Green Chem. 2008, 10, 59-66.

66. Zhao, D.; Fei, Z.; Ang, W.H.; Dyson, P.J. A strategy for the synthesis of transition-metal nanoparticles and their transfer between liquid phases. Small 2006, 2, 879-883.

67. Yang, X.; Fei, Z.; Zhao, D.; Hang, W.H.; Li, Y.; Dyson, P.J. Palladium nanoparticles stabilized by an ionic polymer and ionic liquid: A versatile system for C-C cross-coupling reactions. Inorg. Chem. 2008, 47, 3292-3297.

68. Mehnert, C.P.; Cook, R.A.; Dispenziere, N.C.; Afeworki, A. Supported Ionic Liquid CatalysisA New Concept for Homogeneous Hydroformylation Catalysis. J. Am. Chem. Soc. 2002, 124, 12932-12933.

69. Hagiwara, H.; Ko, K.H.; Hoshi, T.; Suzuki, T. Supported ionic liquid catalyst (Pd-SILC) for highly efficient and recyclable Suzuki-Miyaura reaction. Chem. Commun. 2007, 2838-2840.

70. Wan, L.; Zhang, Y.; Xie, C.; Wang, Y. PEG-supported imidazolium chloride: a highly efficient and reusable reaction medium for the Heck reaction. Synlett 2005, 12, 1861-1864.

71. Reetz, M.T.; Westermann, E. Phosphane-free palladium-catalyzed coupling reactions: the decisive role of Pd nanoparticles. Angew. Chem. Int. Ed. 2000, 39, 165-168. 
72. Cassol, C.C.; Umpierre, A.P.; Machado, G.; Wolke, S.I.; Dupont, J. The role of Pd nanoparticles in ionic liquid in the Heck reaction. J. Am. Chem. Soc. 2005, 127, 3298-3299.

73. Astruc, D.; Lu, F.; Aranzaes, J.R. Nanoparticles as recyclable catalysts: the frontier between homogeneous and heterogeneous catalysis. Angew. Chem. Int. Ed. 2005, 44, 7852-7872.

74. Slagt, V.F.; de Vries, A.H.M.; de Vries, J.G.; Kellogg, R.M. Practical aspects of carbon-carbon cross-coupling reactions using heteroarenes. Org. Proc. Res. Devel. 2010, 14, 30-47.

75. Pryjomska-Ray, I.; Trzeciak, A.M.; Ziòlkowski, J.J.Z. Base-free efficient palladium catalyst of Heck reaction in molten tetrabutylammonium bromide. J. Mol. Catal. A 2006, 257, 3-8.

76. Arduengo, III, A.J.; Harlow, R.L.; Klim, M. A stable crystalline carbene. J. Am. Chem. Soc. 1991, 113, 361-363.

77. Nolan, S.P. N-Heterocyclic Carbenes in Synthesis; Wiley- VCH: Weinheim, Germany, 2006.

78. Glorius, F. N-Heterocyclic Carbenes in Transition Metal Catalysis; Springer-Verlag: Berlin, Germany, 2007.

79. Handy, S.T.; Okello, M. The 2 Position of Imidazolium Ionic Liquids: Substitution and Exchange. J. Org. Chem. 2005, 70, 1915-1918.

80. Gayet, F.; Marty, J.-D.; Lauth-de Viguerie, N. Palladate Salts from Ionic Liquids as Catalysts in the Heck Reaction. ARKIVOC 2008, 61-76.

81. Von Schenck, H.; Akermark, B.; Svenson, M. Electronic Control of the Regiochemistry in the Heck Reaction. J. Am. Chem. Soc. 2003, 125, 3503-3508.

82. Deeth, R.J.; Smith, A.; Brown, J.M. Electronic control of the regiochemistry in palladiumphosphine catalyzed intermolecular Heck reactions. J. Am. Chem. Soc. 2004, 126, 7144-7151.

83. Cabri, W.; Candiani, I. Recent Developments and New Perspectives in the Heck Reaction. Acc. Chem. Res. 1995, 28, 2-7.

84. Xu, L.; Chen, W.; Ross, J.; Xiao, J. Palladium-Catalyzed Regioselective Arylation of an ElectronRich Olefin by Aryl Halides in Ionic Liquids. Org. Lett. 2001, 3, 295-297.

85. McConville, M.; Saidi, O.; Blacker, J.; Xiao, J. Regioselective Heck vinylation of electron-rich olefins with vinyl halides: is the neutral pathway in operation? J. Org. Chem. 2009, 74, 26922698; and references cited herein.

86. Amatore, C.; Godin, B.; Jutand, A.; Lamaitre, F. Rate and Mechanism of the Reaction of ArylPalladium Complexes ligated by a bidentate P,P ligand with an Electron-Rich Alkene (Isobutylvinyl Ether) in Heck Reactions. Organometallics 2007, 26, 1757-1761.

87. Amatore, C.; Godin, B.; Jutand, A.; Lemaitre, F. Rate and Mechanism of the Reaction of Alkenes with Aryl-Palladium Complexes ligated by a bidentate P,P ligand in Heck reactions. Chem. Eur. J. 2007, 13, 2002-2011.

88. Calò, V.; Nacci, A.; Monopoli, A.; Ferola, V. Palladium-Catalyzed Heck Arylations of Allyl Alcohols in Ionic Liquids: Remarkable Base Effect on the Selectivity. J. Org. Chem. 2007, 72, 2596-2061.

(C) 2010 by the authors; licensee Molecular Diversity Preservation International, Basel, Switzerland. This article is an open-access article distributed under the terms and conditions of the Creative Commons Attribution license (http://creativecommons.org/licenses/by/3.0/). 